\title{
On Geography and Technology
}

\section{By}

Graeme Williamson, B.Sc. (Honours)

\begin{abstract}
A thesis submitted to the Faculty of Graduate Studies and Research in partial fulfillment Of the requirements for the degree of Master of Arts
\end{abstract}

Department of Geography and Environmental Studies

\author{
Carleton University \\ Ottawa, Ontario
}

2002

C August 2002, Graeme Williamson 
National Library

of Canada

Acquisitions and Bibliographic Services

395 Wellington Street Ottawa ON K1A ON4 Canada
Bibliothèque nationale

du Canada

Acquisitions et services bibliographiques

395, rue Wellington

Ottawa ON K1A ON4

Canada
The author has granted a nonexclusive licence allowing the National Library of Canada to reproduce, loan, distribute or sell copies of this thesis in microform, paper or electronic formats.

The author retains ownership of the copyright in this thesis. Neither the thesis nor substantial extracts from it may be printed or otherwise reproduced without the author's permission.
L'auteur a accordé une licence non exclusive permettant à la Bibliothèque nationale du Canada de reproduire, prêter, distribuer ou vendre des copies de cette thèse sous la forme de microfiche/film, de reproduction sur papier ou sur format électronique.

L'auteur conserve la propriété du droit d'auteur qui protège cette thèse. $\mathrm{Ni}$ la thèse ni des extraits substantiels de celle-ci ne doivent être imprimés ou autrement reproduits sans son autorisation. 
The undersigned recommend to

The Faculty of Graduate Studies and Research

Acceptance of this thesis

On Geography and Technology

Submitted by Graeme Williamson, B.Sc. (Honours)

in partial fulfillment of the requirements for

the degree of Master of Arts
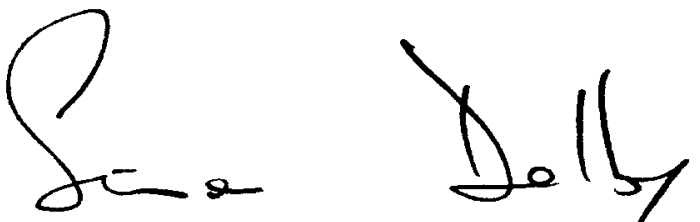

Chair, Department of Geography and Environmental Studies

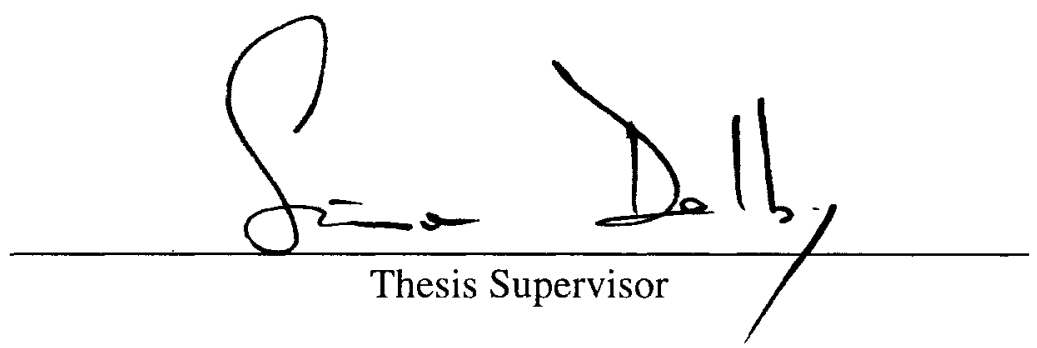

Carleton University

August, 2002 


\begin{abstract}
This thesis inquires into the relationship between geography and technology. The study takes as its point of departure the question of how the world appears in the modern context and more specifically the implications of globalisation. Technology is clearly a pervasive feature of modern society and has been studied in various ways. The intention of this research was to explore technology beyond its specific instrumental qualities and to look into how it might be producing a specific conceptualisation of the world. This is accomplished through the development of the concept of the world as technopresence, which is drawn from the ideas surrounding technology presented by Martin Heidegger and Bruno Latour. The world as technopresence is then used to examine the writings of three prominent human geographers (David Harvey, Derek Gregory, and Doreen Massey) with the objective of examining what re-thinking technology might bring to their geographies. As one of the concerns about the current configuration of the world is the continued degradation of the environment, this thesis closes with speculations about what thinking about technology might offer for a shift from a technologically oriented society to a more ecologically oriented one.
\end{abstract}




\section{Acknowledgements}

I would like to thank my advisor, Dr. Simon Dalby, for his willingness to help me work through a difficult topic. I am grateful for all the attention he has given to the production of this thesis, through his continued enthusiasm, support, and guidance about the subject of technology. I am particularly grateful for his efforts in our discussions to keep me focused on the issues and his valuable comments on earlier drafts which were always insightful and carefully thought out. I would also like to thank my second committee member, Dr. David Bennett, whose initial comments on the first draft helped me to form a stronger argument by pointing out some obvious weaknesses that had to be addressed. I appreciate the time he took to review my work and his open and frank commentary.

I would also like to thank my peers, for their willingness to discuss issues about technology. In particular, I would like to thank Andrew Baldwin, Shawn Donaldson, Lisa Huisman, Kumari Karunaratne, John Milton, and Ralph Perrault for lending an ear and asking the difficult questions.

I would also like to thank Hazel Anderson for always keeping me on track and looking out for my best interests.

Finally, I would like to thank my wife, Tammie Williamson, for all her support and patience. She was always there to build up my confidence and to keep me going when times got tough. Thank you for your understanding, encouragement, and for seeing the light at the end of the tunnel, even when I could not. 


\section{Table of Contents}

Acceptance Form

Abstract

iii

Acknowledgements

iv

Chapter 1 - Introduction: Thinking Technology and Geography

1.1 Introduction

1.2 An Opening for Geography and Technology

6

1.3 Outline of Thesis

Chapter 2 - On Building a Theory of Technology:

The Bridge from Heidegger to Latour

2.1 Introducing Technology

2.2 Heidegger's Conception of Technology

2.3 The Modern World: The World as Picture

2.4 Latour's Technology

2.5 The World as 'Technopresence'

Chapter 3 - Geographers and Technology

3.1 Technology as Instrumentality

3.2 Some Geographic Investigations of Technology

3.3 The Inevitable Rise of GIS in a Technopresent World

58

3.4 Moving Beyond Specifics

Chapter 4 - The Geography of David Harvey:

Is 'The World' Really Shrinking?

4.1 Introduction

4.2 Locating Technology in a Marxian Analysis

4.3 Rescuing Technology form Capital

4.4 Space-Time Compression: Is the 'world' really shrinking? 76

4.5 The World beyond Capitalism 
Chapter 5 - Thinking Technology in Derek Gregory's Geographical Imaginations

5.1 Introduction

90

5.2 Origins of 'the World'

92

5.3 Gregory’s Postmodern Writing of a Postmodern Geography

102

Chapter 6 - Doreen Massey's Geography: Globalisation, Place, and Technology

6.1 Introduction

6.2 Massey's 'Power-Geometries' and the Reining in of Globalisation 108

6.3 Space-Time and Technopresence

Chapter 7 - Re-Thinking the World from Technopresence to Ecopresence

7.1 The Geographical Imperative

7.2 Thinking the World as Ecopresence

7.3 Shifting from Technopresence to Ecopresence

References and Select Bibliography 


\section{Chapter One \\ Introduction: Thinking Technology and Geography}

The prominence of contemporary critiques of technology is not surprising at the end of a century which has suffered through two world wars and countless smaller ones, totalitarianism of the left and right, genocide, a nuclear arms race, the ongoing destruction of the biosphere, and other social disorders of unparalleled magnitude. If this bloody history and an arguably suicidal future are the results of modern technology... then it is time to subject to critical scrutiny the presuppositions of the rationalistic and modernistic attitudes so essential to it.

- Michael E. Zimmerman

\subsection{Introduction}

Technology is a subject that has been an intimate component of the development of geography as a discipline and geography in general. It is woven into the very fabric of modern life, in such a way that it affects everyday life in innumerable ways and simultaneously fades into the background of thought. Wherever and whenever 
technology works it disappears from our concern, whereas when it doesn't work, or produces consequences that are undesirable, it is that which is of most concern.

Today, particularly in the 'Western' world, technology surrounds us. It has altered conceptions of space, time and nature. It has made possible the superficial appearance of " $a$ world". It has affected fundamental human activities, including communication, mobility (transportation), modes of production, modes of war, social organisation and inevitably relationships to nature. It has played a significant role in the toxification of immediate and remote environments. It has also been appealed to for solutions to many of the problems it has created. Following from the undeniable extent of technology's presence in modern society and its possible role in the unfolding of many of the horrors, described by Zimmerman, then a thorough examination of, 'the presuppositions of the rationalistic and modernistic attitudes so essential to it', is certainly warranted.

This thesis will begin to open up one of many possible ways into thinking about technology for geographers. There are some basic assumptions about technology and modernity that will be held here. The first, and most significant assumption, is that the world can be made into a better place. Second, following this initial point is that simply creating 'new' technologies will not solve some of the underlying problems associated with the technology that was to be replaced. And finally, that thinking about technology as something more than just the physical and material gadgets, techniques and practices present and observable in society, will be a useful undertaking in identifying the problems with the current engagement with technology and present potential directions that can lead to a new human-technological relationship. 
I would like begin this thesis with a personal account regarding the relevance of technology for geography. Following this, the next section will expand upon the academic justification for following such a path. This will be followed with an outline describing how this work will unfold. First, however, I will begin here by recounting a story which led me to begin thinking about the relationship between technology, time, space, nature, and inevitably geography.

One day in August 1998, I was to make my way to my cousin's wedding in Lake Tahoe, California. However, the day was to begin in a very different location, the woods of Algonquin Park in central Ontario. At around 6:30 am, my brother and I found ourselves on highway 60 leading from Huntsville into Algonquin Provincial Park. Coming around one bend, we had to quickly brake as there was a large Bull Moose standing in the middle of the road. The moose seemed to take little notice of us and took his time sauntering off the road. Around 15 minutes later, we were standing on the dock waiting for our sister to arrive. It was a cool morning and the mist was still lingering over the surface of the lake. It was quiet at the marina, and suddenly we were treated to a show by a pair of loons that had made there way close to the dock. We sat there quietly our eyes trained on this pair of birds, who are just as much a part of the image of Ontario's 'cottage country' as the moose we had just seen. Shortly, following this, the sound of a small motor boat broke the still morning sending the loons off to seek solitude in another location. My sister arrived at the dock and we continued on our journey.

By the early afternoon, we had arrived at Pearson International Airport in Toronto, boarded a plane and were on our way to Reno, Nevada (the closest airport to our final destination). Upon arrival, we were greeted by a friend of our cousins, who was to take us on to a house we would be staying at in Lake Tahoe. The trip to Tahoe was beautiful. We climbed into the mountains, winding along the road, finally ending up at our destination in an affluent new neighbourhood tucked into the side of a mountain. We arrived just in time to watch the sun set over the California Mountains, the view was spectacular. This day, which had begun with watching the sun rise in the misty early morning of central Ontario, ended with a brilliant orange California sunset. 
What is striking about this story, and makes this day stand out in my memory, is that embedded in the images of the obvious beauty of both surroundings, is the technology that made such a day possible. It was shortly after this that my attention began to be focussed on how technology influences geography. Following from some preliminary investigations, I very quickly found, to my surprise, that geographers were not dealing explicitly with any theory of technology, and consequently, appeared not to be thinking about ways that technology has altered conceptions of space, time, and spacetime, themes that, in my understanding, are fundamental to the foundations of the discipline of geography.

Of course this is but one interpretation of what concerns geographers. As geography remains a fractious discipline, to say the least, this understanding will suffice for the purpose of this thesis. Consequently, the myriad debates that envelope contemporary human geography, not to mention the continuing physical/human divide within the discipline, will not be directly addressed within the scope of this study. However, the general theme of thinking about technology presented in this thesis is intended, in part, to encourage all geographers to consider the implications of technology within the scope of their work, whether they dismiss my argument, object to it strongly, or agree in principle.

When broken down, my story of that day in August 1998 is full of allusions to the power of technology to transform the world we are living in. That is to say, that it is not hard to see that technology permeates almost every facet of our daily lives. From the alarm clock that woke me up at some extraordinarily early hour (... the mechanisms of the clock, the power generation and infrastructure that ran it, standardised time, etc.), to 
the car that we were driving, the boat that carried my sister to us, and the airplane that took us across a continent (the parts, the fuel including extraction, refinement, and distribution, the highway, etc.), technology was at once the underlying force governing our actions and was simultaneously concealed in the fact that the actions led to the results that we had expected. However, in this study I would like to go beyond merely breaking each specific technology down to its components of production and use, and focus on the larger picture of what technology is, what it has become, and how it is operating within the contemporary world.

This thesis is not intended as one which is anti-technology or anti-science. Instead it intends to question technology, and by proxy science, and consequently it seeks to go beyond the treatment of technology as 'instrument' and science as 'truth discovered'. I am aware that science as "truth discovered" has been challenged for sometime, most intriguingly through chaos theory and quantum physics. However, it still appears that beyond these frontier movements within science itself, the vast majority of scientific research is appealed to by society as a firm basis for justifying most political decisionmaking. This of course includes quasi-scientific social science studies. Much of which, as will be shown through this thesis, can be considered as a manifestation of what is underlying the 'modern-technological' age. In fact, I suggest that technology has become part of the modern (western) human condition. In order to question technology, by all accounts a 'big' question, one must turn to the type of inquiry best suited to thinking through questions that are at the basis of our condition. As such, this work will prepare the way for focussing attention on the question of technology by re-thinking its place and consequently situating it well within the concern of contemporary geographers. To do 
this I will examine the ideas of two philosophers who have engaged technology beyond its usual instrumental definition, Martin Heidegger and Bruno Latour, although the majority will primarily be derived from Heidegger. In doing so, I intend to build a theory of technology that will reflect on the questions of 1) what is underlying the concept of modern technology?, 2) how the modern world appears in relation to technology?, 3) what is the significance of this relationship for geography and geographers? And 4) what are the possibilities for shifting the directions of society's unfolding away from an almost exclusively technological orientation to a more ecological one?

\subsection{An Opening for Geography and Technology}

Although my interest in the relationship between geography and technology began with a personal experience, thought about technology necessarily has implications for academic geographic inquiry. With the current unfolding of modernity as globalisation, its most recent configuration, the world is being created by processes and interactions that are almost infinite in scope and as a consequence invariably complex. The process of globalisation, referred to here, is that of the current neo-liberal economic expansion of primarily western capitalist interests based on a long history of a distinctly western philosophical understanding of the world and its contents. However, as Massey (1999a) asserts, "this vision of neo-liberal globalisation, then, is not so much a description of how the world is, as an image in which the world is being made," (p.17). Massey continues, "what has been forgotten in this iconic economics with its implicit inevitabilities is that economic globalisation can take a variety of different forms... for, crucially, the material and the discursive interlock: the way we imagine globalisation will 
affect the form which it takes," (Massey, 1999a: 16). There are likely many who view the current path of globalisation to be either positive or something that is leading to a better world. I, however, do not. I believe that there have been significant problems related to many of the practices and mechanisms in place to facilitate a world market and international trade. Not least of all the difficulty of ensuring that the environment is afforded serious consideration within the decision making framework by those in control of the economic instruments that have spurred globalisation to its present state. This thesis will proceed from a position that views the current path as based on certain assumptions about the world. Indeed, it is precisely the underlying assumptions of the world that will be called into question. As such, this study inquires into those presuppositions that mobilise these basic taken-for-granted assumptions about the world, which are manifested in the current unfolding of modernity in the direction observable today.

This world facing geographers today is one that presents innumerable opportunities for specialised areas of study as is reflected in the ongoing fragmentation of geography departments throughout the 'west'. However, for geographers there is always 'a world' that is essentially at the centre of their concern. As such, there have always been geographers that are willing to wade into the murky waters of thinking about the bigger picture, beyond specifics. There have been various avenues into this line of thinking, always as part of a search for a more accurate view of how the whole can be represented, a way that can hold a reality, defined in advance, still for long enough to get a good grasp of it. Consequently, the way into thinking about the world has to fall upon a facet that can be said to be omnipresent throughout most processes. As such, there have 
been efforts to think through the world using historical materialism, with its attendant notions of capitalist modes of production, feminism, with its notions of a gendered landscape, and the unfortunate catch-all of postmodernism, with its penchant for celebrating differences. For this study, the way into thinking about the world lies in a thorough examination of 'technology', that singular word/concept/phenomenon that has profoundly altered reality and for all intents and purposes has made the creation of ' $a$ world' a possibility. It is through this uncharted realm that this work will begin to try to make sense of what kind of world is unfolding as a result of the current process of globalisation. This thesis will enquire into technology as a world-disclosing horizon, which has remained strangely foreign to geographers who have always been in someway concerned about the world and engaged with some form of technology.

As the $20^{\text {th }}$ century has drawn to a close and the $21^{\text {st }}$ century begins to chart its course, the world facing contemporary geographers is one that is emerging as increasingly complex and less certain than that which dawned at the turn of the last century, as can be extrapolated from Toffler's book Future Shock (Toffler, 1970). Although a considerable part of this uncertainty is the result of how modern technology has come to be used and the kind of world that has resulted from its acceptance, there is simultaneously a growing wave of scepticism with the dominant faith in science as the keeper and purveyor of 'truth' and technology as neutral instrument (Braun and Castree, 1998; Cronon, 1995; Haraway, 1991; Latour, 1990). Although this scepticism has been written into the literature of several disciplines, it is only recently beginning to gain some ground within geography (Crang and Thrift, 2000). The last significant rise in scepticism, in the west, occurred in the $17^{\text {th }}$ century and led to the slow overturning of the Catholic 
Church doctrine as truth, resulting from the Reformation and the Scientific Revolution, the enlightenment, as well as I suggest, the increasingly prolific exploration and colonisation by the dominant European powers (Clarke, 1998 [introduction to Meditations and Other Metaphysical Writings]). This culminated in the metaphysical writings of Descartes, in the 1640 s, whereby an entire way of knowing was legitimated by a philosophically grounded foundation in The Meditations (Descartes, 1998 [1641]). Just as Plato and Aristotle had transformed the path of western philosophy with their writings, Descartes cemented the 'modern' mode of disclosing the world through his metaphysics. Perhaps, what has been witnessed throughout approximately the past 100 years of critical thought, are the beginning seeds of discontent with the current dominant way of knowing and a growing search for an alternative path through which the world can unfold.

The problem, however, is not with science and technology themselves, as these are simply ways of revealing the world; it lies in the fact that these have become the only legitimate ways of revealing the world. To say that science and technology represent the 'only legitimate ways of revealing the world', is not to say that no other modes of revealing are present within society, after all there are still poets, artists, musicians, and writers. Rather, science and technology appear to hold a dominant position with respect to government and business, as well as, social organisation, more generally. I have yet to see a proposed development take directly into account a poem or painting when considering whether to proceed as planned or not. However, the artistic capturing of a site might still inspire some local residents to challenge the project. But again this would 
be considered through some technical evaluation of 'public opinion' and even the value and prestige of the artist as determined by the 'art' experts.

What is also observable is that anything that results from these modes of understanding is measured solely in one direction. With this, come the unidirectional notions of 'progress' and 'development', whereby, anything that is new (from the west) is viewed as advancement. By unidirectional progress and development, I am obviously not speaking of temporal directionality. Rather, I am speaking to the idea of advancing, which implies positive movement 'forward'. What is conspicuously missing here is any effective assessment of technology, and science for that matter, that allows for a classification other than advancement. As well, advancement implies that there is some goal in sight, something that one is advancing towards.

Among the objectives of this thesis, which is in line with the growing scepticism, is an attempt to disrupt the singular notions of 'progress' and 'development' so as to allow for human activities to be measured in directions other than 'forward'. These singular directions are evident in the collective perception of that odd temporal net that is reflected in notions of 'advanced capitalist' nations and 'developed' countries vs. 'developing' nations. It will also look into whether modern society has become an appendage to technological systems that in turn guides human interaction, as well as human-environment interaction, which profoundly influences how a society might unfold. Following from this, this thesis will close with a proposal for an alternative way to guide human interaction, one that will be based on notions of ecology (as opposed to the science of ecology) and would permit a new ethical component to emerge out of the 
now dominant technological fatalism that appears to have gripped western society with its current blind faith in globalisation as it exists.

The notion of ecology here refers to the incorporation of humans into a broader understanding of the environment. Generally, this view sees the current configuration and practice of social organisation as often working against or working in spite of the surrounding environment, hence the continuous toxification of the land, air, and water. The notion of ecology speaks more broadly to an ideological social shift, rather that the study of specific components of an ecosystem and their interactions. However, the former does rely to a large extent on what the latter produces.

\subsection{Outline of Thesis}

To begin with the question of what is underlying the concept of modern technology, I will focus primarily on Heidegger's writings about the larger implications of technology and modern society in general. I have found in Heidegger several ideas that I believe make him an appropriate figure for the kind of questioning of technology that I want to undertake in this thesis. First, and most obvious, Heidegger has written extensively on technology. Further, within his writings on technology he attempts to move beyond any specific technological device to examine what is common to all of modern technology, which he sets apart from all previous technologies. In short, he is searching for what might be understood as the 'essence' of technology. With such an examination, Heidegger pushes the direction of thinking about technology away from the more common approach of regarding technology as simply a neutral tool for human use, 
void of any deeper implications for the human condition. For Heidegger, "the major sense of 'modern technology' will always be the contemporary disclosure of all things as raw material... [and] also [sic] the industrialism and the modernist world view made possible by that disclosure," (Zimmerman, 1990: XIII). With this unique reversal of the role of technology, from something produced through the modern application of knowledge to producing a specifically modern understanding of things in the world, Heidegger opens a way of thinking about technology that has the potential to challenge the dominant characterisation of the contemporary human-technology relationship. The concern with this current human-technology understanding is that it seems to continue to lead to more 'problems' with every 'solution', that is the perfect machine has yet to be invented. Therefore, given the extent to which technology permeates so many facets of the modern world, where it simultaneously opens and closes new possibilities, enables and constrains actions, and where it is present yet fades into the background of thought, a closer examination of this curious phenomenon is certainly warranted. Heidegger's interpretation of technology offers an intriguing option for building a new understanding of the human engagement with technology.

Second, Heidegger makes the distinction between the terms 'world' and 'earth'. This is a distinction that should be familiar to many geographers, yet I do not see it receiving the attention it deserves. It is precisely this distinction that is so essential for understanding what is to follow in this thesis. The difference between the 'earth' and the 'world' lies in the fact that the 'earth' consists of the totality of all entities, all possibilities and all histories, whether they have been articulated or not. Whereas, the 'world' refers to what has been explicitly articulated, an appropriation of earthly things 
into a specified (defined in advance) framework, which understands (discloses) entities in accordance with certain classifications or categories. For Heidegger, "entities belong to the 'earth', which can never be made fully present in any world," (Zimmerman, 1990: 226). Following this he, "concluded that the 'hidden law of the earth' is an impenetrable mystery," (Zimmerman, 1990: 227). Therefore, much of Heidegger's focus, “criticised both metaphysics and the science which arose from it because they presupposed both that there is an enduring, objective 'structure' to things, and that reason is capable of discovering this structure," (Zimmerman, 1990: 227). Again, through the twentieth century, this conceptualisation of science has been called into question and many of its initial claims that an absolute truth is attainable through the pursuit of science have given way. However, in spite of this shift in ideas about scientific certainty, considerations about technology have not necessarily followed suit. Rather, it is still largely regarded as the application of scientific knowledge.

Heidegger's philosophical position flows directly from the 'earth/world' distinction. His hermeneutic phenomenology, as it is often labelled, sought to overcome some of the limits that were reflected in Husserl's phenomenology, by extending the concept of, "to the things themselves," to, "letting that which shows itself be seen from itself in the very way in which it shows itself from itself," (Heidegger, 1962: 58). For Heidegger, the 'things themselves' can never be fully known, they appear always through an interpretation. Thus, by transforming hermeneutics from an 'epistemological' pursuit to an 'ontological' one, Heidegger's focus shifts to the concept of 'being-in-the-world'. This, "involves a movement between an anticipatory pre-understanding, which comes from our very 'beingness' and our role as knowing subjects with knowledge about 
objects in the world," (Dictionary of Human Geography (Barnes), 2000: 335). In a sense then, Heidegger's project sought to elucidate the conditions necessary for the rise of a particular world situated within a particular history, and how it is that entities present themselves as they do, in accordance with that world and that history; hence 'being-inthe-world' gives a sense of being 'thrown' into an already present world that carries with it a language and knowledge base that allows for the disclosure of things in a particular sense, in that they are given meaning in relation to their place in the world.

Finally, to inquire into technology, or rather, into the technological age (the modern age), what must be kept in mind is what type of 'world' exists for things to show themselves as 'ready-at-hand' for uptake into a technological system or grid. Taking as a starting point, it would appear that in a particular epoch, human behaviour is shaped by the way in which things manifest themselves. That is, "if things manifest themselves as creatures of God, people treat things in one way; if things reveal themselves as nothing but raw material, people treat them in another way," (Zimmerman, 1990: XV). Therefore, although the 'things themselves' cannot be known outside of a particular conceptualisation, there are certain inherent limits to the possibilities of what things should become. I do not believe I am alone in perceiving that the contemporary disclosure of things is problematic to say the least. Indeed, as fragmented as the environmental and social movements are, there seems to be a common discontent with the current configurations of social organisation and it is instead with the question of how to proceed that inevitably produces the divergence of opinions. In a particularly salient passage, Zimmerman (1990) describes some of the concerns with the technological disclosure of things. 
If for something 'to be' simply meant for it to present itself in accordance with the categories imposed by an historical epoch, then there would be nothing problematic, for example, about animals presenting themselves merely as objects in the laboratory or as commodities on the factory farm. Nor would there be any reason even to pause in the face of the possibility of storing aborted human fetuses in cold-storage warehouses as a spare-parts 'resource' for infants with genetic problems. Certainly, animals and fetuses can present themselves as objects and commodities, but Heidegger would have said such a disclosure is inappropriate," (Zimmerman, 1990: 227).

It is precisely the existence and possibility of the appearance of these 'things' that has led me to search for an explanation of how 'western' society has reached this point. I find the above examples, along with the emergence of genetic engineering, the continued toxification of our land, air, and water, and the increasing dependence on modern technology to generate the necessities for life, a rather unnerving situation. As Heidegger has inquired into the conditions necessary for the production of such a world, I believe that taking some of his ideas seriously and integrating them into a geographic study is a useful undertaking. Again, there are many ways into thinking about 'modern technology', what follows in this thesis is an examination of one of those paths and a elaboration on its potential significance for geographers, as well as the possibilities thinking about the disclosure of entities can bring to sketching out new directions. As Heidegger is a relatively controversial figure in philosophy, I presume that many readers will not share my enthusiasm for his evaluation of technology, and may dismiss this argument altogether. However, in pursuing this direction, I hope that it will significantly raise the profile of technology among geographers and that they will, at the very least, begin to consider its role within their own research and more generally within their own lives. 
The above will provide the foundation for an understanding of what might be called 'the essence of technology', which will be developed in more detail in Chapter two. Following from Heidegger's opening of a philosophy of technology I will use the works of Bruno Latour to further Heidegger's ideas of technology and to track how technology manifests itself as part of contemporary society. Although Latour's work is primarily associated with Actor Network Theory (ANT) and the Sociology of Scientific Knowledge (SSK), I will not dwell on either but instead will focus on the themes of technology that are pervasive in his writings.

I have chosen Latour, to supplement Heidegger's evaluation of technology, partly because geographers have recently begun to incorporate his ideas into the discipline (Bingham and Thrift, 2000; Crang, Crang, and May, 1999; Braun and Castree, 1998) and partly because at the outset he appears to challenge Heidegger's ideas. However, in spite of Latour's seemingly oppositional stance towards Heidegger, they are both engaged in the same debate and, as I will show, generally express similar concerns. As Hacking (1983) proclaims, it is often more useful to focus on the commonalities that make a debate possible in the first place, rather that to focus exclusively on the differences. By focussing on what is common to both Heidegger and Latour, I intend to strengthen the foundation of what I will come to call the world as technopresence. When Bingham and Thrift (2000) were contemplating why to include Latour (alongside Serres) in Thinking Space, they concluded that:

They have sought to repopulate space and time with all the figures that have been stripped away by an idea of abstract division, by concentrating instead on movement, on process, on the constant hum of the world as the different elements of it are brought into relation with one another, often in new styles 
and unconsidered combinations. In other words they are attempting to rediscover the richness of the world... (p. 281)

It is precisely the reintroduction of these figures (technology in particular) that makes the case for employing Latour in this thesis. Latour, with his rigorous empirical research that brings technological characters back into the world, provides an appropriate supplement to Heidegger's meditative 'thinking' about technology. However, despite the separation between the methods used by Heidegger and Latour, their interpretation of technology and modernity, are remarkably similar.

The crucial point here is that, for both Heidegger and Latour, technology is something that shows up within the world. That is it does not exist as something distinct from the social, indeed technology, humans, and nature are 'thrown' together as a constitutive whole which make 'things' intelligible to us in a particular way. "Although it is important not to conflate epistemology and ontology (the notion that our ideas generate the world), in technoscientific networks epistemology and ontology increasingly implode - the world 'outside' the laboratory comes to mirror the world 'inside'," (Braun and Castree, 1998: 27). In a significant way Latour's work also leads to the re-historicising of technologies and nature (which will become important for Chapter 7), where their material presence is shifted from simply being an unproblematic background or ontological given to being 'things' that are represented in the larger framework of the world. That is they are articulated in a particular way. It is this notion of 'articulation' that Latour brings to the argument set out in this thesis. Accordingly, this will begin to answer the question of how the modern world appears in relation to technology (Chapter 2). 
To answer question three, I will begin with a brief, but thorough, review of how technology has been addressed by geographers. I will first focus on geographers who have addressed specific technologies, such as transportation, communications, and agricultural technology (as well as the inevitable inclusion of GIS). This will be done to elaborate on the idea of technology as something that is conceived to be merely instrumental, neutral, and usually value-free (Chapter 3). As well, I will describe the research undertaken to determine the extent to which technology has been discussed within geography. The point of this thesis is to move beyond such conceptions and to write technology back into its socio-spatio-historic context as an integral part of modern social development and organisation. As this study will be engaging technology through philosophical inquiry, I will examine three geographers who have also made attempts to answer questions relating to the modern human condition. David Harvey, Derek Gregory, and Doreen Massey have all written extensively in the philosophical genre, in an attempt to think through the world that is at the centre of concern for contemporary geographers. Although, there are numerous geographers that are participating in philosophical debates and investigations, I have chosen these three because of their prominence within geographic literature and due to the nature of this thesis, I would be unable to engage every geographer who is writing about some significant philosophical issue.

David Harvey, arguably the most recognised name in contemporary geography, has produced an extraordinary amount of work pertaining to the human condition under late modern capitalism. For the purposes of tractability, I will confine my analysis to four major works: The Limits to Capital (1982), The Condition of Postmodernity (1989), Justice, Nature, and the Geography of Difference (1996), and Spaces of Hope (2000). 
Harvey's work often makes references to technological change and the resulting influence on geography, yet, as with many Marxists, he remains reluctant to separate this from an account of the history of capitalism. My intention is to use the theory of technology developed in Chapter 2 to analyse Harvey's meticulously crafted historical materialism, with the intent of elaborating on the allusions to technology that pepper his works (Chapter 4). As a result, by infusing a theory of technology within his works, thus making the technology an explicit component of the narrative, this thesis intends to move his work beyond the scope of the geography of political economy to one that could better understand technology's role in the geography of 'the world'.

The purpose of introducing an explicit theory of technology and comparing it with Harvey's historical materialism is to examine how this might offer some insight into certain social and human-environment relationships set out initially by Marx. In particular, conceptions of nature, space-time compression, and visions for an alternative future will be analysed with an explicit focus on the technological angle. It will be shown that raising the profile of technology can significantly re-shape some of Harvey's theories and potentially overcome some of the stumbling blocks that typically confront an historical materialist analysis. Finally, the epilogue to spaces of hope will be discussed in relation to the human-technology relationship.

Derek Gregory's, Geographical Imaginations (1994), is a well recognised work within the geographic genre. Gregory goes into exceptional detail in his work to uncover what is at the heart of the modern world facing contemporary geographers. As with Harvey, Gregory also dips his mind into the well of technology periodically and sporadically, yet just as Harvey, he seems to be hesitant to pull technology out of the 
position of instrumentality, a tool of some other actor both creating and playing on the imaginative stage which is the world. By analysing Geographical Imaginations, this thesis will emphasise the technological component in the rich tapestry of difference that Gregory constructs in his philosophical exposé of the contemporary world and the contemporary discourse of geography (Chapter 5).

Although he goes into considerable detail in explaining Heidegger's 'enframing', I find he loses track of some of the more significant points that can be made about the role of technology as the book progresses. However, this seems to be his intention, to open a space for multiple voices to be heard. As encouraging as this might be, I have nonetheless examined certain aspects of his text and also his style of writing. There are many positive points that can be extracted from Geographical Imaginations, yet for the purpose of this thesis, I admittedly try to contain a book which seeks to free itself from such narrowing visions.

Finally, in Chapter 6, I will examine the works of Doreen Massey, a well known feminist geographer, ideologically based in Marxism. As such, Massey is no stranger to turning the discipline on its head, and writing a geography that typically picks up on all the differences and nuances that have been generally left out of mainstream geographic literature, material that is usually ironed over by the universalising stroke of the pen. Of the three geographers I have selected, Massey initially seems to have taken the conception of technology the furthest. However, by analysing Massey's PowerGeometries and the Politics of Space-Time (1999), Space, Place, and Gender (1994), High Tech Fantasies: Science Parks in Society, Science and Space (1992), and Spatial Divisions of Labour: Social Structures and the Geography of Production (1984), I intend 
to extend her accounts of technology further and to situate them within the theory of technology that will be developed in Chapter 2. As Massey's writings typically tend to treat technology in much the same way as conventional historical materialism (albeit with particular attention paid to the implications of uneven development for women), I will tend to focus more on her conceptions of place and its relationship to globalisation.

Following the analysis of these three geographers, and having examined technology in relation to the geographies they construct, I will turn my attention to the place of technology within the discipline. Drawing on the geographies that emerge from a re-thinking of technology's role in social organisation, I will continue with an elaboration of the new world that results from the combination of the ideas from Chapters $2,4,5$, and 6. As such, Chapter 7 will examine the world with an explicit focus on technology. Using the idea of the world as technopresence (developed in Chapter 2), I will look at how the world might unfold with a shift to ecopresence (developed in Chapter 7). Notions of ecology, 'nature', and the environment will be found throughout this thesis, as these often form the basis for the current discontent with the systematic technological world. Furthermore, as one of the main intentions of this study is to open a way for geographers to think about technology's relationship with geography, this chapter will close with speculations on the potential implications for geography and geographers once technology takes its place within the geographic imagination. But, first one must understand what technology is. 


\title{
Chapter Two \\ On Building a Theory of Technology: \\ The Bridge from Heidegger to Latour
}

\begin{abstract}
The consequences of our actions take hold of us, quite indifferent to our claim that meanwhile we have 'improved'.

- Nietzsche
\end{abstract}

\subsection{Introducing technology}

To say that technology is a pervasive feature of the modern world would seem at first to be self-evident. Why, then, should we go any further, is this not blatantly obvious to anyone who stops to look around? The initial reply would be of course, yes, technology is everywhere. However, this thesis will look beyond the obvious qualities of technology and instead look at technology as an organising force, intricately enmeshed within the modern human condition, where technology is nowhere. This chapter will begin with a thorough examination of Heidegger's later works (Post 1935, as described by Zimmerman, 1990; Scheibler, 1993) with an explicit focus on drawing out some of his key ideas about technology. I will then continue with a brief overview of Latour's focus on technology with the intent of showing the connection between Heidegger's philosophy 
and the more recent rise of 'science studies'. This connection, which speaks to the practical engagement with technology that is implicit in Heidegger's work, will then be used to develop the idea of the world as technopresence. This will be the primary concept, heavily influenced by Heidegger, which will be used to analyse the technological engagement of geographers in chapters $3,4,5$, and 6 .

The concern of this thesis is with the impact 'modern technology' has had on society and the environment. There are few, if any, aspects of modern life that are not in some significant way engaged with the technological. The following employment of Heidegger is intended to depart from a more conventional take on technology and to bring some new insight into how technology is understood. The purpose of such an undertaking is to offer a different approach to thinking about technology, not for the sake of simply adding an extra voice to discussions on technology but rather to examine the prospects that might flow from Heidegger's interpretation of technology. This approach views modern technology as being primarily derived from, "a one-dimensional mode of understanding what things are", as opposed to the view that sees it being a more sophisticated version of primitive tools, resulting from, "historical trials and errors of material practices", (Zimmerman, 1990: XIV). Where the latter sees the sophistication of modern technology as the application of a parallel development in scientific knowledge, the former sees it rising out of a progressively narrow conceptualisation of things that increasingly presents everything as raw material. It is this latter view of technology that is of interest for the purpose of this thesis, as a serious examination of this idea should provide for a significantly different assessment of technology's place in society and consequently offer new possibilities for thinking about how to overcome some of the 
problems associated with the rise of modern technology (i.e. worker alienation, environmental degradation, etc).

In short, it is how we see the world that has likely led western society to the position that it finds itself, a position, I for one, feel can be improved. Modern technology then becomes the measurer of all other technologies. Is this not observable in contemporary society? Yes it is. Often other non-western technologies, and by extension civilisations are spoken of as primitive, traditional, ancient, backwards, or even obsolete. Can this be narrowed down to a comparison to any one particular technology in modern society? No, because specific modern technologies are not what endures in western society. This can be seen by the fact that even 'modern' technologies that have been developed in the recent past have been measured by what is 'newest'. If this is so, and I believe it is, then what endures in 'modern' western society is not anything technological (more on this below). Instead we are left with the 'essence' of modern technology as that which endures in modern western society (Heidegger, 1977). It is through this questioning into what is driving modern society forward, and toward what end, that this thesis will progress.

Whether Heidegger is critiqued or championed, his extensive and tremendously influential works on a philosophy of technology, in my opinion, should not be dismissed. In this thesis, I sketch out a preliminary understanding of technology with a thorough examination of Heidegger's ideas. If for few other reasons, Heidegger's work on technology will at the very least provide an opening into thinking of technology beyond the instrumental. As indicated in chapter 1, I believe, he is invariably an appropriate figure to start this inquiry into the relationship between geography and technology. 
Although, Heidegger provides a strong foundation to begin the journey towards (re)thinking technology, it will be shown that he does not provide any strong conclusions or even explain some of the ideas that he introduces. However, perhaps Heidegger's place is to open a way to thinking about technology, to offer a distinctly different approach which has the potential to challenge some basic taken-for-granted assumptions about the world.

Following from this, I will turn to Bruno Latour to add to Heidegger's 'technology' and simultaneously show that their theories of modernity and technology are in fact reconcilable. To this end, Latour does a brilliant job in exposing technology's place in social processes, in particular that of scientific practice. Throughout his works Latour seems to take exception to and to elaborate on precisely the same modernity that Heidegger had sought to investigate. Latour's meticulous untangling of the networks that lie behind current social phenomena expose the processes of modern purification, the act of separating science and society, at its very roots. Again, these very roots are the same that led Heidegger to explore technology.

\subsection{Heidegger's Conception of Technology}

As one of the primary intentions of this thesis is to investigate 'the world' from the realm of world-disclosing horizons, the following detailed explication of Heidegger's philosophy is necessary as this would appear to be outside the boundaries of what is usually classified as geography. As well, Heidegger's distinctive use of language, designed to lead one through thought, needs to be drawn out in this section. Although 
early Heidegger has been consistently appealed to by a number of geographers, usually working under the sub-disciplinary fields of humanistic geography and postmodern geography (Peet, 1998; Johnston, 1997; Relph, 1970), this study intentionally moves into Heidegger's later writings which are explicitly focussed on technology, an area which has yet to receive significant attention. The appeal to early Heidegger, within geography, arose in part within the 'backlash' within the discipline to the quantitative revolution of the 1950s and 60s (Peet, 1998; Johnston, 1997). The immediate intention was to reincorporate human agency back into geographic inquiry. This thesis, however, reflects some aspects that have recently been picked up by other geographers who have begun to examine the implications of Heidegger's later writings, which decidedly leave behind the explicit phenomenological focus on human experience (see Demeritt, 2001; Braun and Castree, 1998).

By examining the modern world as a manifestation of technological disclosure, this study will appear to be unconventional for most geographers who often take that world as their ontological starting point. However, once this line of thinking is brought to light, the connections to the discipline of geography should become evident and the taken-for-granted world that forms the basis for many contemporary geographic studies will be shown as that which requires geography's utmost attention.

Heidegger begins his essay on The Question Concerning Technology (1977), by opening a way for coming into a relationship with the 'essence of technology'. Heidegger continues:

The essence of technology is by no means anything technological. Thus we shall never experience our relationship to the essence of technology so long as we merely conceive and push forward the technological, put up 
with it, or evade it. Everywhere, we remain unfree and chained to technology, whether we passionately affirm or deny it. But we are delivered over to it in the worst possible way when we regard it as something neutral; for this conception of it, to which today we particularly like to do homage, makes us utterly blind to the essence of technology. (The Question Concerning Technology, p. 4)

To answer what Heidegger means by saying that the essence of technology is not technological, it is imperative that an instrumental definition of technology be first brought to light. Heidegger offers two definitions of technology that could be considered as instrumental. First, "technology is a means to an end," and second, "technology is a human activity," (Heidegger, 1977:4). Furthermore, he points out that these definitions belong together, "for to posit ends and procure and utilise the means to them is a human activity," (Heidegger, 1977:4). This will certainly suffice as a definition of technology as instrument. However, Heidegger pushes us to go further, for as he states above, this is the conception of technology that will make us blind to its essence.

These definitions with their propensity towards means and ends and activity point to an understanding in terms of causes and effects, "whatever has an effect as its consequence is called a cause," (Heidegger, 1977:6). Further, Heidegger (1977:6) argues, "wherever ends are pursued and means are employed, wherever instrumentality reigns, there reigns causality." Causality, then, becomes Heidegger's open door to question technology.

Following the word cause back to the Greeks, Heidegger outlines Aristotle's doctrine of the four causes: causa materialis (the material), causa formalis (the form), causa finalis (the ends), and, causa efficiens (the means) (Heidegger, 1977). All four causes belong together in what has been understood as cause, as a 'bringing about', 
'effecting'. However, Heidegger states that the current appropriation of the conception of a cause cannot be that of the Greek conception, as what the Greeks understood as cause had little to do with effecting or bringing about (Heidegger, 1977). The Greeks, Heidegger asserts, instead understood this phenomenon as, "aition... that to which something else is indebted," (Heidegger, 1977:7). This being 'indebted' is then understood as a being in debt to that which is responsible for its coming to presence. In turn, this being responsible for, is not to be understood as a mere cause, where that which comes to presence is the effect. Instead Heidegger re-articulates the four causes as four qualities of being-responsible-for. First, there is the material, that to which the final product owes its substance. Second, is the aspect or idea of the final product, that to which gives form to the product as such. Third, Heidegger states what is most responsible, "is that which in advance confines," (Heidegger, 1977:8). Here he is referring to that which circumscribes, where in, "circumscribing gives bounds to the thing," (Heidegger, 1977:8). This is the vision for which the thing will be used once it has been produced. Heidegger states that, "that which gives bounds, that which completes, in this sense is called in Greek telos," (Heidegger, 1977:8). Telos, Heidegger claims, has been repeatedly misinterpreted as a purpose; however, he insists that it is that which is responsible, "for what as matter and for what as aspect are co-responsible," (Heidegger, 1977:8). This form of being responsible for is that which begins the thing upon its way into arrival. Finally, Heidegger attributes to the craftsmen or artist, that fourth way of being responsible for the final product. For it is through them that the thing can come into appearance and 'lie before us ready for use'. It is to this person that the three previous 
ways of being responsible for are indebted, "for the 'that' and the 'how' of their coming into appearance," (Heidegger, 1977:8).

Following from this, Heidegger now substitutes the verb aitia (to 'occasion') for the essence of 'causality', "thought as the Greeks thought it," (Heidegger, 1977:10). To explain 'occasioning', Heidegger uses the term poiessis, bringing-forth. So from out of all of this Heidegger has made the distinction between causality as a bringing-about and occasioning as a bringing-forth. Where is the difference? Bringing-about would refer to a situation whereby, through certain causes, certain effects are expected to result (means and ends), the mode of revealing is thus removed from the picture. Whereas bringingforth would inherently imply a mode of revealing, that is it would include the 'how' that which is to 'lie before us ready for use' comes to be present, or ready at hand.

Heidegger uses the example of a sacrificial silver chalice to illustrate the above description of a thing coming into appearance. Heidegger (1977:7-8) describes this process as follows:

Silver is that out of which the silver chalice is made. As this matter, it is coresponsible for the chalice. The chalice is indebted to... the silver for that out of which it consists. But the sacrificial vessel is indebted not only to the silver. As a chalice, that which is indebted to the silver appears in the aspect of a chalice an not in that of a brooch or a ring. Thus, the sacrificial vessel is at the same time indebted to the aspect of chaliceness. Both the silver into which the aspect is admitted as chalice and the aspect in which the silver appears are in their respective ways co-responsible for the sacrificial vessel.

But there remains a third that is above all responsible for the sacrificial vessel. It is that which in advance confines the chalice within the realm of consecration and bestowal. Through this the chalice is circumscribed as sacrificial vessel. Circumscribing gives bounds to the thing. With the bounds the thing does not stop; rather from out of them it begins to be what after production, it will be...

Finally there is a fourth participant in the responsibility for the finished sacrificial vessel's lying before us ready for use, i.e., the silversmith - but not at all because he, in working, brings about the finished sacrificial 
chalice as if it were the effect of a making; the silversmith is not a causa efficiens...

The silversmith considers carefully and gathers together the three aforementioned ways of being responsible and indebted...The silversmith is co-responsible as that from whence the sacrificial vessel's bringing forth and resting-in-self take and retain their first departure...

Thus four ways of being responsible hold sway in the sacrificial vessel that lies ready before us. They differ from one another, yet they belong together.

Heidegger's example starts one thinking about what is required for something to be brought forth, to come into appearance. In his example the silver is called upon as the raw material, but this has its place within a broader set of practices that are co-responsible for the chalice being produced. However, the three other components of the chalice's coming to be present are equally, if not more important. What is significant to note here, is the elevated position Heidegger attributes to the silversmith, as the connection between the craftsman, the material, the idea, and the vision are all essential to chalice's coming to 'lie before us ready for use'. It is important to keep this in mind as Heidegger moves into considering modern or machine technology, which he regards as synonymous.

Heidegger, therefore, thought the fourfold 'occasioning' as that mode of revealing that held sway in the age of the Greeks and that this mode of revealing was transformed, initially through Plato and Aristotle, that is through Greek productionist metaphysics to 'causality' as the mode of revealing that holds sway in the modern age. That is in order for anything to be present, it must necessarily be 'produced'. This is intriguing as it can apply both to a Marxist view of the importance of modes of production, as well as with a social constructionist view which takes everything to be produced through human interaction and organisation. 
Having questioned the roots of instrumentality and cause, Heidegger now directs his attention towards the roots of technology, which he finds in the Greek technē. Techne as such, "is the name not only for the activities and skills of the craftsman, but also for the arts of the mind and the fine arts... [it] belongs to bringing-forth," (Heidegger, 1977:13). Following from this, techne is a mode of revealing that brings forth that which is not already present. This significantly included 'art' and 'thinking' alongside 'manufacturing', where it refers to knowing in a much broader sense than is attributed to the conceptualisation of technology. In 'essence' then techne is knowing in the broadest sense, and should not be considered as only producing. It is a way of revealing (articulating) entities from within concealment into unconcealment. Continuing from here, the subject of concern for Heidegger, as well as for this study, is what can be called modern technology or machine technology. Modern technology is also a way of revealing. However, it has, according to Heidegger, fallen away from any understanding of ways of revealing, and as will be argued here, it has simultaneously become the dominant way of disclosing 'things' in the modern age.

This is where Heidegger sees the danger arising from the modern disclosure of the world. In, "placing a transcendental human consciousness at the centre, as does the instrumental view, human temporality becomes erased," (Braun and Castree, 1998: 17). By dehistoricising human knowing, "the 'order' of the world is seen as something 'discovered' rather than something that itself requires explanation... [this has] allowed moderns to mistake their 'ordering' of the world with the world itself, and therefore rendered them unable to think the limits of representation - its closures and absences," (Braun and Castree, 1998: 17). Thus, with modern technology operating as a world 
disclosing horizon, the intellectual space necessary for thinking through how the world is ordered is effectively removed and we are consequently left with an 'ordered reality' that has gained a sense of permanency.

Heidegger's distinction between techne $\bar{e}$ as understood by the Greeks and modern technology, understood in terms of means and ends (that is of utility) forms the basis for what follows. "The revealing that rules in modern technology is a challenging," in that it sets-before us how it is the world is to be encountered and challenges-forth (demands) the earth (and society) to fulfill particular functions (Heidegger, 1977:14). This 'challengingforth' is a mode of the 'setting-in-order' which is bounded by technology (thought as means and ends) as a way of revealing. To illustrate, Heidegger suggests that the historic fields sown and worked by farmers are inherently different to fields that are farmed today. Pastures and fields in the past belonged to and were part of the history of a place, in that there was a rooted connection and a sense of knowing which stretched beyond the present into the past. They were part of a world, a way of living (being) and consequently had meaning beyond the ends they produced. In contrast the field, in the modern age, has been set-upon, challenged-forth, to yield a crop with the primary goal of making a living, where, "agriculture is now [part of] the mechanized food industry," (Heidegger, 1977:15). This way of challenging-forth, has led to all things being revealed and ordered as 'standing-reserve' (Heidegger, 1977). "Everywhere everything is ordered to stand by, to be immediately at hand, indeed to stand there just so that it may be on call for a further ordering," (Heidegger, 1977:17). Heidegger continues:

The forester who, in the wood, measures the felled timber and to all appearances walks the same forest path in the same way as did his grandfather is today commanded by profit-making in the lumber industry, 
whether he knows it or not. He is made subordinate to the orderability of cellulose, which for its part is challenged forth by the need for paper, which is then delivered to newspapers and illustrated magazines. The latter, in their turn, set public opinion to swallowing what is printed, so that a set configuration of opinion becomes available on demand. (p. 18)

The above passage illustrates clearly what it is about modern technology that can distinguish it from all other times and technologies, as well as revealing some of Heidegger's deep rooted concerns. It is here that the echoes of the laments made by contemporary environmentalists and social activists begin to come to light. As such, what Heidegger is inquiring into are the very roots of the increasingly present sentiment that there is something inherently wrong with 'how things are'.

Although this line of reasoning could be seen to be pointing towards the idea of technology as a transcendent autonomous entity, this is not exactly the case. In fact, what is necessary first is that modern western society is challenged-forth as part of the standing-reserve, more originally than nature as it is humans that will order what is real as standing-reserve. Heidegger (1977) suggests that this is evident in references to 'human resources' that are currently part of a larger vocabulary that invokes the fundamental conception of the modern human condition. Furthermore, the Human Genome Project and biotechnology also point to the current blurry lines between what is human and what is technological. Both of these projects seem to be showing that we have indeed become convinced that 'we' too are revealed as 'standing-reserve'. However, Heidegger (1977) argues that it is:

precisely because man is challenged more originally than are the energies of nature, i.e., into the process of ordering, he is never transformed into mere standing-reserve. Since man drives technology forward, he takes part in ordering as a way of revealing. (p. 18) 
I would suggest that this can still be the case, even in the presence of transgenics, fertility technologies, and organ transplants, although, if the lines between human and technology were blurred before, they have become almost imperceptible today.

The concept of modern technology as a way of revealing everything as "standingreserve' forms the basis for what follows in Heidegger's thinking about technology. Zimmerman (1990) states that:

For Heidegger, 'modern technology' had three interrelated meanings: First, the techniques, devices, systems, and production processes usually associated with industrialism; second, the rationalist, scientific, commercialist, utilitarian, anthropocentric, secular worldview usually associated with modernity; third, the contemporary mode of understanding or disclosing things which makes possible both industrial production processes and the modernist worldview. (p. XIII)

It is this third point, which is of primary interest to this study. It is the 'mode of understanding or disclosing things' which gathers everything into a singular direction of ordering reality in a specific way. To this Heidegger attributes the concept of 'enframing' as the essence of modern technology, that way which reveals all, through an ordering, as 'standing-reserve' (Heidegger, 1977).

It is through this line of thinking that Heidegger reverses the usual relationship between modern science and modern technology. Following from the above argument Heidegger suggests that it is because of the 'essence of modern technology' holding sway through 'enframing' that modern science has unfolded in the manner it has. That is to say that everything was already present at hand as 'standing-reserve' and thus allowed for modern science to apprehend the world as such. Heidegger continues: 
Accordingly, man's ordering attitude and behaviour display themselves first in the rise of modern physics as an exact science. Modern science's way of representing pursues and entraps nature as a calculable coherence of forces. Modern physics is not experimental physics because it applies apparatus to the questioning of nature. Rather the reverse is true. Because physics, indeed already as pure theory, sets nature up to exhibit itself as a coherence of forces calculable in advance, it therefore orders its experiments precisely for the purpose of asking whether and how nature reports itself when set up in this way. (p. 21)

Therefore, through this line of thinking, although modern technology seems historically to have followed from the application of modern science as an exact science, the way of revealing the real as an orderable whole had actually preceded the rise in modern science. "Because the essence of modern technology lies in Enframing, modern technology must employ exact physical science. Through its so doing, the deceptive illusion arises that modern technology is applied physical science," (Heidegger 1997:23).

For Heidegger then, it is the essence of modern technology, thought from the transformation of bringing-forth (poēisis) to a bringing-about (cause) that first begins western society on the path towards a singular rational ordering that gathers everything into its systematic unfolding, manifested and culminating in modernity and most recently in globalisation. Enframing, as that which begins western society on a path, is for Heidegger a 'destining' (Heidegger 1977). However, 'enframing' is not to be understood as a fateful inevitability that must be seen through to its completion. Instead, Heidegger (1977) argues that:

The essence of modern technology lies in Enframing. Enframing belongs within the destining of revealing. These sentences express something different from the talk that we hear more frequently, to the effect that technology is the fate of our age, where 'fate' means the inevitableness of an unalterable course... [Instead] destining in no way confines us to a stultified compulsion to push on blindly with 
technology or, what comes to the same thing, to rebel helplessly against it and curse it as the work of the devil. (p. 25-26)

The purpose of this in depth examination of Heidegger's evaluation of technology was developed to provide the necessary foundation for understanding what could be meant by world-disclosing horizon. By thinking technology as a mode of revealing, one that compels a certain ordering of the world, it becomes possible to imagine how that world would appear. Although I have presented Heidegger's argument in a manner that would appear to accept everything he has said as given, this was not the primary intention. Indeed, I have drawn on Heidegger because, at the very minimum, he forces one to re-consider some deeply held assumptions. Perhaps, his characterisation of science as 'exact' now seems to be railing against a long since discarded $19^{\text {th }}$ century mechanicalreductionist conceptualisation of science. However, having been initially trained in the sciences, I suggest that although it has been conceded that absolute certainty and objectivity are often unattainable, they still remain as yardsticks that can be approached but never entirely achieved. What has arisen, instead, is a preoccupation with probability. As well, unless I am horribly mistaken, there still remains within science the appeal to 'scientific laws' (e.g. law of gravity, law of thermodynamics, etc.). In fact, it seems science still holds many of the characteristics that were reflected in $19^{\text {th }}$ century practice (e.g. the focus of research on components such as a specific gene, or protein sequence, the quest for a Grand Unified Theory). I suggest that much of what is counted as scientific uncertainty today is derived less from 'frontier' physics, and more from the incredible proliferation of scientific research throughout the past century. As research is now associated, in a significant way with business, it is the direct competition for funding 
dollars, publications, 'breakthroughs', and prestige (status) that has led to the situation of competing accounts of certain phenomena. Furthermore, with the appeal to science for justification of certain interests of various organisations (a residual from the days when scientific evidence was irrefutable), the status of scientific results has not dropped off significantly, they are simply open to more discussion. As one environmental activist once put it, there is always a scientist available to support your project, "we call them biostitutes," (Dorn, J., 1994 [Friends of the Wolf]).

Again, although there are many challenges that can be presented against particular elements of Heidegger's work, his thinking on technology continues to offer an intriguing take on the production of the modern world. Thus, what has been arrived at, through this consideration of Heidegger's work, is that realm of thought that exposes the worlddisclosing horizon of technology. It is from this position of a world producing force that technology becomes something that must take its place in the scope of concern of contemporary geographic literature. From this understanding of technology, I will now turn towards how this has been manifested in what is called the 'modern worldview', which is rapidly producing 'the world' through the increasing reach of globalisation.

\subsection{The Modern World: The World as Picture}

Metaphysics grounds an age, in that through a specific interpretation of what is and through a specific comprehension of truth it gives to that age the basis upon which it is essentially formed.

- Heidegger

The above section developed the idea of technology, as that which grounds the modern age as a world-disclosing horizon. In this section I will begin to inquire into the 
appearance of the modern world. This will provide the necessary transition to move from Heidegger to Latour.

Technology as a world-disclosing horizon is grounded first through the metaphysical writings of Descartes. "What it is to be is for the first time defined as the objectiveness of representing and truth is first defined as the certainty of representing, in the metaphysics of Descartes," (Heidegger 1977: 127). The representational reality that arises here is the 'how' the world is disclosed through technology thought out of 'enframing'. What defines an age as an age therefore is a specific framework, which holds certain epistemological foundations as its ground. From out of this ground, that which is, is circumscribed within a specific binding which defines what is counted as 'real'. Within the modern age, that which is giving bounds to things, is the singular legitimate hold on truth (thought fact) which is modern science. As has been presented above in this paper, Heidegger makes a strong assertion that when thought 'essentially' modern technology (as enframing) precedes that of modern science. Thus, the 'modern age' can be thought of as synonymous with the 'technological age'. In turn, then this has to be thought as the world as technopresence, the world that arises out of the technological mode of disclosing entities encountered in the world.

I am questioning, here, how the modern world appears, and as such, it becomes necessary to introduce two concepts, that of the 'world' and that of the 'world-as-picture' (Heidegger, 1977). The difference between the two can be seen in, "the contrast between the idea of the world, with its attendant notion of dwelling, and of the world-as-picture, with its attendant notion of representability," (Simpson, 1995: 44). For the modern age, it is the world-as-picture that describes primarily how the world unfolds. Here the, "world 
picture, when understood essentially, does not mean a picture of the world but the world conceived and grasped as picture," (Heidegger, 1977: 129). It is the world that can be held in that representational 'enframing', whereby vision is granted primacy in knowing. Literally, 'seeing is believing', where the world-as-picture leads to an 'occularcentric' worldview.

The ability to be able to represent space visually and with increasing accuracy, therefore, became the modern geographic reality. Following the increasing scientific rigour attached to mapping (distancing from human subjectivity/more technological), aerial photography (further detached/more technological), and finally satellite imagery (the most detached/the most recent technology), the world literally became synonymous with its visual representation. Likewise, other 'entities' began to appear through the employment of technologies. Microbes, DNA, the ozone layer, thermal ocean currents, and so on have all become 'things in the world'. The implication of their appearance is not limited to their interest for science, nor of their material presence, rather as they show up within the world they extend beyond their technological representations to affect politics, daily individual practices, social and environmental causes, in short the very configuration of the world itself. Latour, then, with his quest to draw attention to what he calls the 'missing masses', becomes an appropriate figure to compliment Heidegger's meditative thinking on the technological age. "Even if it is now obvious that the missing masses of our society are to be found among the non human mechanisms, it is not clear how they get there and why they are missing from most accounts," (Latour, 1992: 248). Although, Latour goes on to answer his own question, I feel that linking his ideas to Heidegger will provide more useful for understanding technology as set out in this thesis. 
Reconciling the two will be the primary objective of the next section, which will set the stage for the appearance of the world as technopresence.

\subsection{Latour's Technology}

As the philosopher, Bruno Latour, has recently gained currency within the discipline of geography (Dalby, 2002; Barnes, 2001; Robbins, 2001; Crang and Thrift, 2000; Crang, Crang, and May, 1999; Barnes, 1998; Braun and Castree, 1998) and that he is concerned with technology specifically and modernity more generally (Latour, 1999; Latour, 1993; Latour, 1986) he is an appropriate figure to discuss within the framework of this thesis. Although, he is probably most often associated with Actor Network Theory, and the micro-sociological implications of technological artefacts within the human condition and social organisation, I will not specifically address these facets of his research within this study. However, the intention of this section is to demonstrate the underlying similarities between Heidegger's philosophy of technology and the broader philosophical discussion surrounding social constructionism. As such, I will simply sketch out some of the connections between the two here and this will hopefully serve to show the potential for employing both philosophers within a single inquisitional framework.

Latour, if one were to take what he has written at face value, that is without any thought given to what he is saying, would initially seem to be adamantly opposed to Heidegger and his disciples. I am not, however, so easily convinced that this is the case, and moreover, I will suggest that in fact Latour is generally raising the same concerns 
that Heidegger had posited in his own peculiar way. Bruno Latour (1999) writes, in his opening piece to Pandora's Hope, "Do you Believe in Reality?" about, "the forgotten fork in the road... the once-passable path now lost in a thicket of brambles." Similar to Heidegger, Latour places this choosing a pathway, squarely on the shoulders of Descartes, who first placed our minds-in-a-vat gazing out at some externalised 'nature' out there (Latour, 1999). This positing of, what can be assumed to be Latour's ' understanding of the origins of what he calls 'the modern constitution' (Latour, 1993), fits precisely within the similar grounding of Heidegger's conception of the metaphysical beginning of the modern (technological) age. The reconciling of differences, however, does not simply rest on the temporal location of the modern era and in fact, the connections between these two philosophers become more clear the further one thinks through the implications and inferences embedded in their works.

Hacking (1983) advises that is often more useful to look for the similarities amongst seemingly oppositional stand points within a debate, as the fact that they are engaged in debate at all speaks to the necessity of some underlying agreement about and recognition of the 'issue at hand'. It is my contention that both Latour's and Heidegger's concern with modernity, and the absences there within, reveal that they actually have more in common, than it would initially appear. As such, even though Latour makes the retrospective claim that 'we have never been modern', he goes to painstaking lengths to reveal the processes, theories, and practices that have produced such a delusion in the first place (Latour, 1993). Similarly, although Heidegger goes to great detail to describe the rise of the modern mode of disclosing the world, from out of the technological enframing traced originally to Plato and Aristotle, and culminating in Descartes' 
metaphysics, he consistently points out that a technological mode of revealing is not a fait accompli (Heidegger, 1977). Furthermore, Heidegger argues that the primary 'problem' with modernity is that 'moderns' have mistaken their ordering of reality with reality itself (Heidegger, 1977). Likewise, Latour's engagement with 'the modern constitution', makes it clear that the purification of 'things' into their respective 'constitutional' categories of natural and social, or science and politics, never actually holds beyond the discursive dimension, as most activities, actors, things, technologies, etc. fall somewhere in between, and are always present as 'hybrids', those which by their very nature or employment by society can not be classified either way (Latour, 1993).

Demeritt (2001) beautifully illustrates that the connections between Latour and Heidegger actually run much deeper, and as he is a geographer the capacity of the discipline to absorb the two will be implicit. In his discussion, Demeritt argues that the debate surrounding the notion of social constructionism typically centres around two competing views, those of social construction as refutation of science's truth and social construction as unmasking of the inevitable partiality of its formulation (Demeritt, 2001). However, Demeritt asserts, these distinctions are, 'somewhat simplistic', (Demeritt, 2001). Consequently, he sees these competing views as leading to a dead end argument and as such builds his own social construction category, 'heterogeneous constructionism', "to signal that the facts of nature are not given as such but emerge artifactually as the heterogeneously constructed result of contingent social practices," (Demeritt, 2001: 311). The significance for this study is that he credits this form of social constructionism to Latour and Braun and Castree, among others, and then attributes their ideas as necessarily connecting in and owing to Heidegger. 
Demeritt's argument in making the above connection and his explanation of heterogeneous constructionism is well articulated and it would be useful to reproduce some of it here. Demeritt argues that Latour draws his insights from Heidegger's idea:

That nature and the other-things-in-the-world are disclosed to us as objects through practical engagements that configure them in ways that are recognizable for us and transforming of us. Heterogeneous constructionism does not deny the ontological existence of the world, only that its apparent reality is never pre-given; 'reality' is only ever realized as such through the configuration of practices that make existence manifest, throwing human subjects into a particular world of order and intelligibility... Heterogeneous constructionism provides a way of acknowledging that the world 'matters' without taking for granted either the particular configuration of its matter or the processes by which it may be realized for us... In this Heideggerian sense, equipment [technology] is not simply an inert tool but also the interdependent languages, conceptual categories, and ways of being-in-the-world through which it becomes a tool-for something. Similarly, the 'real' world is not independent of but inseparable from the particular constellation of social practices through which its form is enframed along with our own... The practical engagements understanding involves reshape the way subjects and objects are thrown tngether as beings-in-the-world. (Demeritt, 2001: p.311-12)

This passage links almost perfectly Heidegger, Latour, and geography. As the primary focus of this thesis is not specifically heterogeneous constructionism, what becomes significant from the above quote, is the relationship of technology beyond its purely instrumental form, but rather as a way of being-in-the-world. The inherent contingencies built within the above description, link this discussion closely with Latour's conception of 'networks'. What I have argued within the section on Heidegger's technology, and again is relevant to Latour here, is that the problem he sees with the modern age, is that it has predominantly 'taken the particular configuration of the world for granted' and simultaneously concealed 'the processes by which it may be realized for us'. These two 
dominant themes within the modern age have resulted in the direct manifestation of the world as technopresence.

\subsection{The World as 'Technopresence'}

What becomes relevant for geography from the writings of these philosophers is that the world can now be said to be dominated by technopresence. That is to say that the modern world is one that is technopresent at any given moment. For something to be technopresent, means that it is already thought to be in a certain way, which is that it is revealed in a manner consistent with the enframing that Heidegger has elaborated on.

By beginning with Heidegger and continuing on through Latour, the world as technopresence takes form. This should be conceptualised as: 1) that modern technology creates a particular relationship with things in the world. It is that technology compels earthly entities to present themselves as functional components that will fit within a specific ordering. The earth is demanded to supply energy, material, etc. And, 2) That everyday engagement with technology, where it mediates, filters, constrains, and directs human action, serves to perpetuate the relationship to things through a technological framework. When things show up as raw material they are treated as such. The world is populated with technopresent entities (humans included), each with their function and ready to take their place as part of a technological whole. These two concepts held in simultaneous operation, disclose the world in a particular manner. This could be understood as the world-disclosing horizon of technology.

The world as technopresence, then, is the political/environmental manifestation of the world-disclosing horizon of technology. The word at once holds both notions of the 
political and the environmental (scientific) together in the same conceptual framework. In doing so, it seeks to understand the modern age as emanating out of a singular metaphysical foundation. This in turn produces singular conceptions of 'progress' and 'development'. As this spreads across the planet, through globalisation, the multiple worlds that exist in spatially different locations are gathered into the systematic ordered unfolding of the world as technopresence. That is all space and its contents are mobilised and folded into the representational capacity of the technopresent world, which transforms differences into spatial and temporal representations within 'the world'. Today, in western media, academics, politics, economics, social and environmental activism 'the world' is spoken of confidently, where it has become effectively a representable 'whole' which can function in the necessary manner so as to perpetuate the idea of interconnections, which in turn legitimise the rise of 'the world'.

The idea of an interconnected 'whole' is appealed to by economists and environmentalists, conservationists and developers, as well as nationalists and anarchists. Yet, underlying such a conception is the disconcerting notion that 'world making' has somehow been completed in a profound way. The geographic grid, has thus given rise to a conceptual framework (as precarious, and precocious, as it may be), that has the necessary function of gathering in everything encountered so that it fits within the understanding of the world as technopresence. When thinking of the world as technopresence here, the modern 'nation-state' can be thought of as the collection of technologically present entities that when considered together form the basis of "the world'. Following from Heidegger and Latour, the nation-state, far from being an unproblematic container of political organisation, in fact is a technological entity itself. 
Practical engagement with the state as a 'thing-in-the-world' has profound implications

for how politics can be undertaken and more generally how the world is visualised and consequently 'known'. Political geographer John Agnew (1998) captures this idea of the significance attached to visualisation of the world for 'world politics' in his Geopolitics: Re-Visioning World Politics. He argues that thinking 'world politics' would be impossible without a global vision. Agnew (1998) describes his project by examining the assumptions behind this global vision:

The acquisition and perpetuation of this vision - the sense of a world-as-awhole that powerful actors must survey and subdue - are traced through the history of early modern cartography, the theorising of 'one world of humanity', imperial cosmologies, colonial economics, formal geopolitical models, and the global ideological polarisation of the Cold War. The purpose is to show the cumulative historical basis to global geographical visualisation: How the Earth was made into the World. Thinking about the world as a whole was not a one-time thing, established once and then taken for granted. It had to be constantly reproduced in changing economic and technological circumstances to remain effective. Seeing the world as one and then dividing it into a hierarchy of places have required relating thinking about the world to changing material conditions even as the a priori assumption of wholeness is perpetuated. (p. 7 , italics added)

The implications here for thinking the world as technopresence, with the state as a technopresent entity, are obvious. The implicit connections to Heidegger's 'world-aspicture' and Latour's 'missing masses' show Agnew (alongside others in 'critical geopolitics') are working to re-think the embedded assumption of the state as the embodiment of political action. For something to count within 'world politics', then, the modern geographic imagination necessitates that it show up within the framework of 'the world'. This, of course, allows for the usual discourse of an inherent 'inside' and 'outside', whereby even those phenomena that are counted as 'outside' are counted so 
from an oppositional relationship of 'otherness'. This is certainly not a new conception for geography, especially for geopolitics (as was shown with Agnew), but my attempt here is to extend such a conceptualisation to the world-disclosing horizon of technology, with the desired effect of bringing into geographic thought, questions regarding what kind of world necessarily exists for 'things' to appear as they do in the modern age.

As such, this much seems true, that technology holds sway, whether it is seen in the neo-fatalist attitude of the modern economists, or in the singular directional measurement of scientific results. The economists, in their oedipal quest for market driven solutions, have written any meaning or connection with the world out of the scope of their concern. So long as the world is accessible for the commodifying practices of global capitalism and the necessary people understand the associated discourses of property and economy, there are no worlds outside of 'the world'. Furthermore, with the configuration of nation-states that now provide the only vehicles for global negotiation (thought international), there is the unfortunate consequence that binds all people of the world into this system whether they have consciously decided to participate or not. This is not to say that there aren't pockets of resistance that exist, however, resistance only becomes resistance when that which is being resisted has gained sufficient authority and acceptance so as to set up the necessary power relationship inherent in the word resistance itself.

As well, science and technology seem to be consistently viewed as advancing and their results are always measured as progress, no matter what the consequences of these might be. Even the creation of weapons of mass destruction (chemical, biological, 
nuclear) have always been seen by the collective modern understanding as advancements in scientific knowledge and/or technological progress.

What is measuring advancement here? Is it the enlightenment ideal of producing a better society (emancipation and self-realisation), or is it the culmination of a view that holds technology as the world-disclosing basis for understanding, for which the enlightenment project is simply one of its manifestations? As will be suggested throughout the remainder of this study, what is of interest in these questions, and will hopefully go some way into explaining them, is that the idea of the world as technopresence provides an intriguing avenue for thinking these conceptions through. However, I must caution the reader that I am in no way suggesting that the world as technopresence will act as a meta-narrative that can explain or account for everything. Instead, I believe that it might prove useful for beginning to think about how the world is produced, as 'the world'. Following from this, it will attempt to extend geographic inquiry beyond examining 'things' in the world, and will consequently flip the question so as to ask what kind of world exists where the 'things' that usually concern geographers appear in the first place. Inevitably, what will also come to light here is that it has been only a modern phenomenon where the 'world' itself has become a 'thing', about which we can speak intelligibly. 


\section{Chapter Three \\ Geographers and Technology}

Geography is what geographers do.

\subsection{Technology as Instrumentality}

If in fact geography is what geographers do, then it would follow that as geographers have continually engaged with forms of technology, technology would certainly show up in discussions about geography. However, this, surprisingly, is not the case. A quick glance through the indices of RJ Johnston's (1997) Geography and Geographers and Richard Peet's (1998) Modern Geographical Thought, reveal no entries for technology. Flipping to The Dictionary of Human Geography (2000), there is also no entry for technology (amusingly the space where technology should appear is in between TAYLORISM and TELEOLOGY). Well, there must be some kind of mistake. So we go on. A look at the Canadian Association of Geographers, the Association of American Geographers, and the Institute of British Geographers' websites also all similarly fail to 
show any signs of specialty groups investigating technology. How is this possible, given the fact that even the earliest recognised geographers were engaged with some form of technology? Have (human) geographers, after years of overcoming colonial beginnings, racially based environmental determinism, and early geopolitical ambitions, once again become complicit in a technological system of domination? The trick is one must look further, as technology as an instrument is certainly present in contemporary and historical geography; it just remains hidden conceptually, theoretically, and philosophically.

Thus, upon re-orienting our inspection of technology to that of specific instruments and techniques, it suddenly appears to be everywhere in geography. This search reveals discussions on agricultural technologies, cartographic technologies, communications technologies, information technologies, geographic information systems (GIS), and transportation technologies, among many others. In a less obvious way technology also shows up in the geographies of governmental systems, financial systems, labour management systems, land-use planning, social organisational systems, trade mechanisms, and urban planning systems, not to mention its inherent employment in virtually every physical geographic study. It appears then, that geography does indeed engage with technology in, at the very least, the recognition that technologies exist. Inevitably the question must arise, that if technology is so present within the discipline, why is there the odd silence on discussing technology outside of specifics?

In researching geography's relationship with technology, I began with a Geobase search to begin to assess whether my presumption about the lack of discussion on technology was correct. Amusingly, by using a database to search for relevant articles 
and books relating to geography and technology, the list of 'available' information was technologically mediated (perhaps a sign that I was on the right track). This search failed to turn up anything that was explicitly speaking to the ideas of technology I was looking to explore. The majority of texts that have been useful for the development of this thesis, fell within the 'social construction' (Demeritt, 2001), 're-thinking nature' (Braun and Castree, 1998; Cronon, 1995), and 'the science question' (Latour, 1999) genres. Typically, these reflected geographers (as well as those outside the discipline) who were concerned with social constructionism and 'continental philosophy' more generally. As many of these were not explicitly engaged with 'technology', I have not counted them in this chapter, rather their ideas are drawn on more generally throughout this work (see for example Braun and Castree, 1998; Cronon, 1995; and Demeritt, 2001).

The next section will provide a brief overview of three geographic journals, to assess what geographers are saying about technology. The Canadian Geographer, Transactions of the Institute of British Geographers, and the Annals of the Association of American Geographers, will be reviewed for the 12 year period between 1990 and the most recent issue of 2002 (Canadian Geographer: 46(1); Transactions of I.B.G.: 27(1); Annals of AAG: 92(1)). These journals were selected to assess the degree that technology was being addressed in 'mainstream' Anglo-American geography. As this thesis is seeking to question technology generally and geography and geography as a discipline specifically, three of the representative journals of the major English speaking geographic associations were chosen. The intention here was to examine what geographers were saying about technology within the forum of the discipline's less specialised geographic publications. As these journals typically cut through the broad range of issues significant 
for geography, they provided an excellent opportunity to gauge the position of technology within the geographic imagination.

Having already researched connections to the technological question posed in this thesis, these journals were to be set up intentionally to show, by contrast, how technology is conventionally being addressed. However, alongside the large volume of articles dealing with specific technologies or technological change there were a few pieces that dealt explicitly with Heidegger or Latour. These were drawn into the general body of this thesis and will not appear here, although it is important to note that my original presumption about mainstream geography proved to be not entirely true. The time period chosen for the journal review was based partly on it being the most current and for a reasonable length of time so as to discern specific trends (assuming the Geobase search would pull up earlier writings on technology). Also, it coincides with the significant rise of both GIS and the internet, two technologies that are particularly relevant to geography. The intention of this review, however, is to show that technology is consistently present within geographic inquiries, but is not being discussed as something beyond the specific geographies of specific technologies. However, by my own theory of technology (the world as technopresence), developed in the previous chapter, almost every article will contain implicit connections to technology. The review therefore, will focus only on those articles that explicitly invoke some form of technology. Following this, Chapters 4, 5 , and 6 will continue this discussion further by analysing the depth of critical thought given to technology by three of the disciplines largest contributors and will consequently be considerably more detailed. 


\subsection{Some Geographic Investigations of Technology}

As suspected, most of the articles that appeared in the journals mentioned above dealt almost entirely with what I have referred to as technology as instrument. That is, they have focused on specific material manifestations of certain technologies and their implications for geography. In this section I will briefly outline three main classifications of articles concerned with technology: economic or industrial technology, communications or information technologies, and computational technologies. GIS will be discussed in the following section.

The above categories were chosen after reviewing the selected journals. Having initially pulled articles by their explicit reference to technology (title or abstract), or by an obvious link (i.e. internet, cyber-, communications, etc.) the selections were then further classified. The categories chosen were based on the natural division of themes that seemed to be consistent throughout most of the selected articles. Articles that did not fit into these classifications were either discarded or if they were of particular relevance to this thesis they have been included in the broader framework informing this study (these were limited to papers by Massey, 1999b, 1995b; Livingstone, 1990, 1998; and Demeritt, 2001, 1996).

The vast majority of articles seemed to investigate technological change within certain industries and their implications for spatial and regional distributions and social organisation. Following this, there was a considerable amount of attention given to communications technologies, specifically the internet. This is certainly not surprising, 
considering the period for the review I have undertaken, 1990-2002, coincides with the introduction and rapid proliferation of the internet amongst the general population (primarily within the advanced capitalist nations, of course). The third classification of computational technologies, acts more as a default category for articles that discuss technology but do not seem to fit within the other categories that I have specified. I have designed these classifications to be intentionally broad, so that they can accommodate a range of writings that approach a specific subject from a variety of angles.

Economic geography and geographic investigations into industrial organisation, location, and change, have been consistently popular within the discipline since at least the 1950s, and arguably much earlier (Johnston, 1997). Given the increasingly neo-liberal economic practices that have been continuing to grow since the late 1970s, especially within in Britain, Canada, and the United States (the three nations that are predominantly represented in the selected journals), it is not surprising that there was a considerable amount of attention given to technological change within the field of economic geography. However, this field is particularly diverse and consequently represents a number of competing discourses converging on a rather complex subject matter.

As the 1990 s began with a recession which was then followed by an economic boom, particularly in the 'technology sector', it was astonishing that there were so few articles that addressed this issue. The 'technology sector' which accounted for much of the economic boom throughout the middle to late ' 90 s was really only mentioned specifically in three articles (Janelle, 2001; Ó hUallacháin, 1997; Bathelt and Hecht, 1990). Given the incredible rise in the 'high-tech' sector during the 1990s and its prominence within the media and government rhetoric, I am confused by the lack of 
attention to given this phenomenon by geographers. The very nature of these industries, which typically cluster within a well defined region, would appear to lend themselves to geographic analysis. However, as this is not explicitly the focus of this thesis, I will constrain myself to simply identifying what has been written, which remains, at least within the selected journals, to be very little.

Continuing with the theme of economic/industrial geography, it would appear that the continuing transformation of manufacturing processes from 'fordist' modes of production, to those of a more 'flexible' production (to borrow Harvey's terminology) garnered a significant amount of attention. The technological connection that is inherent within such a transition was the focus of a number of articles. This primarily focused on the effects of technological change within certain manufacturing sectors and their resulting transformation of labour relations (the unfortunate rise of 'downsizing') and the locating of related industries within a certain proximity due to the rise in 'outsourcing' (Rigby and Haydamack, 1998; MacPherson, 1997; Rose and Villemarie, 1997; Elmes and Harris, 1996; Feldman and Florida, 1994; Mather, 1993; Rigby, 1991). The remaining articles related to economic/industrial geography addressed issues through historical materialism or empirically tested specific economic policy objectives (Langton, 2000; Leyshon and Pollard, 2000; Breheny, 1995). Overall, it was found that none of the articles treated technology as anything more than a means to some specific ends, usually measured by economic productivity.

The 1990s, as stated above, also saw the rise of the internet within the general public. This has obvious connections to the rise in the 'high-tech' sector during the late 1990s. However, the articles concerning the internet, or information and communication 
technologies more generally, were found to be considerably more imaginative. As the spatial impact of these technologies are slightly more profound for geography (the creation of new spaces, cyberspace, virtual communities, etc.), they correspondingly received more attention. In a special issue of The Canadian Geographer, geographers were invited to comment on new information and communications technologies and their implications for, "the penetration and use of telecommunications, particularly the internet, in francophone territory, emphasising their role in rural and peripheral regions," (Gilbert and Villeneuve, 1999). As such, this special issue, titled 'Social Space, Regional Development, and the Infobahn', attracted a variety of perspectives on the possibilities and the potential problems with the promotion of primarily French communities through the use of the internet and associated telecommunications (Bertrand, 1999; Cote, 1999; Lefebvre, 1999; Gigon et Crevoisier, 1999; Grasland, 1999; Klein et Carriere, 1999; Manara, 1999; Fortin et Sanderson, 1999; Vidal, 1999). Although, many of the articles examine the social implications of telecommunications technologies, few seem to take technology beyond its immediate effects and consequently fail to examine in any significant detail the philosophical implications of such a technological connection. As the internet is still a relatively 'new technology', even though its pervasiveness in Western English culture makes it seem as though it has been around for longer than it has (my view might be skewed as its significant incorporation into academic settings coincides exactly with my post-secondary academic endeavours), I would speculate, quite safely, that that this will continue to gather momentum as an area for study. As such, articles similar to Paul Adams studies with visual media and the formation of 'new places' will probably start to make their way more prominently into the various 
geographic association journals (see Adams, 1998 post-internet article 'Network Topologies and Virtual Place' and Adams, 1992 pre-internet article 'Television as Gathering Place').

Beyond, the areas discussed above, technology as instrument has made its way into the discipline by the shear utility of and reliance on the computer. As computers have become phenomenally more powerful (read as speed, memory and efficiency) the capabilities for using them to increase 'academic productivity' through writing, calculating, data storage and processing have had a profound impact on the discipline, and the academic community as a whole. For the most part though, most discussions regarding this technology that were found in this review, were laudatory accounts of or promotional venues for certain software packages, or the 'new' employment of potentially more efficient means for processing geographic information (models, databases, etc.) (Fabrikant and Buttenfield, 2001; Armstrong, 2000; Field, 1991). Given the increasing incorporation of 'computers' within academic research, such as the almost exclusive use of Geographic and Academic Databases for research, there was a surprising absence of any serious discussion about the implications of this direction for academic research in general, and specifically geographic research. It seems most geographers are concerned more about the implications of GIS for the discipline, as will be shown in the next section, and have somehow forgotten that much of the information that is used in research is often selected through some form of technological mediation. Even though books and journals are still primarily read in hard copies, thought has to be given to how that reference was found (e-mail list, geographic database search, search engine). 


\subsection{The Inevitable Rise of GIS in a Technopresent World}

It should not be surprising that GIS has risen to the position it has within Geography departments. With the rise in the technological capacity for digital information to be created, shared, and communicated, it was only a matter of time before maps and mapping made the electronic leap. This also fits with the world as technopresence, as the earth's surface has been increasingly represented within a sequence of continually more exacting measurements. The leap to satellites and digital mapping reflects the most recent stage in this development, where computer assisted mapping and space surveillance can be viewed as the most technologically accurate representations to date. This is what the machines have been designed to do. The significance of the quest for the most accurate mapping techniques available still shares some common ground with its pre-digital predecessors. The ability to visually represent the planet's surface has always been linked to centres of power and the ability to control space (see Agnew, 1998 and also Cosgrove, 1994).

With the most recent developments, there now exists the possibility of creating three-dimensional landscapes that allow an individual to 'virtually' wander through a region without ever setting foot on the ground. The obvious implications for modes of conducting military operations here are quite evident (as was witnessed with the Gulf War, Kosovo, and now Afghanistan), although this line of inquiry goes beyond the scope of this thesis. Furthermore, it is not only the military that are using these techniques, but also other organisations concerned with tracking weather patterns, sea ice cover, forest cover, and even the visual mapping of 'invisible' entities such as the ozone layer. These 
developments, by visually representing these phenomena, have resulted in an increased awareness of their existence, and have quite literally 'put them on the map'. But is this not the image of the world as technopresence par excellence? Yes, this has become but one more technological medium through which the 'entities' of the earth are made present in the 'world'. Yet, discussions surrounding the use of GIS within geography have largely remained at the application level.

However, the increasing proliferation of GIS programmes in Geography has met with considerable debate. In fact, there was a special issue forum, in the Annals of the Association of American Geographers, that discussed the idea of "GIS: Tool or Science?" (Wright et al. 1997; Pickles, 1997). Indeed, the GIS debate presented one of the more intriguing discussions on technology, within the 'mainstream' geography journals. Articles addressing GIS related issues ranged from privacy concerns (Curry, 1997), to 'Geographic Information Engineering' (Hoeschele, 2000), affects on decision making (Jankowski and Nyerges, 2001; Ceccato et al., 2002), and communicating geographic information (Goodchild, 2000). Most intriguing was Robbins' attempt to think seriously about the terminology that Bruno Latour offers and its implications for the application of GIS, in "Tracking Invasive Land Covers in India, or Why Our Landscapes Have Never Been Modern" (Robbins, 2001). Although, the discussions surrounding GIS have begun in the direction that could be considered as approaching a serious discussion of technology, as they have questioned the sociological and environmental implications of GIS application, they nonetheless never manage to reach the level of a broader discussion about technology. They remain at the level of discussing a specific technological device. To track broader discussions about technology, it still remains necessary to turn to the 
social theorists in the discipline, and as will be shown in this thesis, they also adumbrate technology's role in social organisation.

Needless to say, the use of GIS in geography remains a constant source of discussion. Unfortunately, it would be unfeasible to reproduce the issues here, so I will simply suggest that the employment of GIS in geographic research offers a particularly significant ground for geographers to consider the role of technology within the discipline, and within the production of a visually representable world more generally.

Articles that employed GIS or remote sensing techniques were quite common throughout the reviewed journals. They were not selected for this review, primarily because to include every study that employed a technological instrument would not be in line with the intentions of this thesis. However, it is significant to note, that starting in 2000, the Annals of the Association of American Geographers began to sort their publications under specific classifications. One of these headings is 'Methods, Models, and GIS', perhaps pointing to its growing significance within in the discipline, or perhaps the positing of GIS among the science side of the equation.

\subsection{Moving Beyond the Specifics}

Although this review was set up to show that geography was engaging with technology in a particular manner, I did find some explicit consideration of some of the ideas that have been presented in this thesis. As stated above, these have been written into the general body of this study, and were not presented in this chapter because they did not directly deal with technology. Overall, the review of these journals revealed, for the most 
part, the kind of engagement with technology that I had expected. However, as the intention of this thesis is to question technology beyond its micro-scale impacts, I will examine, in depth, selected works by three prominent human geographers in the following chapters $(4,5$, and 6$)$. Inevitably, social theorists remain the sole source of any discussions that seek an alternative geographic imagination, one that will move the world in entirely new directions. As geography is a discipline that concerns itself with the world, it seems well suited to discussing the possibilities of recognising alternative trajectories for the further unfolding of human society across the planet, including the removal of a singular framework that accounts for all spatial differences within its own hierarchical, historically determined ordering.

David Harvey, Derek Gregory, and Doreen Massey were selected because they reflect the type of broader thinking that is being appealed to in this study. Furthermore, as all three are quite well recognised within human geography (i.e. they have considerable influence), it would appear to be a worthwhile exercise to consider their works in relation to the nature of technology. In doing so, the following three chapters explore some of their ideas in relation to the world as technopresence as was set up in Chapter two. It is my intention to reflect on how technology is assessed by these geographers, how the world as technopresence stands in relation to their works, and finally what re-thinking technology might offer to their respective interpretations of the contemporary world, modernity, and geography more generally.

As stated earlier in this thesis, the world as technopresence is not intended to offer a new all encompassing view of the contemporary world, rather its significance lies in the reconsideration of the role of technology as well as offering potential insights into 
Harvey's, Gregory's, and Massey's studies. It is my contention that a departure from the conventional assessment of technology might be useful in considering 1) where we are as a society, 2) the level of attention that should be directed towards technology, and 3) what these might bring to sketching out new directions within geographic research. It is this last point that also makes the selection of these three geographers particularly relevant. The common theme that runs through all three of these geographer's collective works is that there is a certain discomfort with the current configuration of the world, and that there has to be a better situation somewhere on the horizon. The hope, then, is that by following a significantly different approach to the consideration of technology that this will open up a path that might aid in 'getting there from here'. 


\section{Chapter Four \\ The Geography of David Harvey: \\ Is 'The World' Shrinking?}

In no way does the machine appear as the individual worker's means of labour... Not as with the instrument, which the worker animates and makes into his organ with his skill and strength, and whose handling therefore depends on his virtwosity. Rather, it is the machine which possesses skill and strength in place of the worker, is itself the virtuoso, with a soul of its own in the mechanical laws acting through it... The science which compels the inanimate links of the machinery, by their construction, to act purposefully, as an automaton, does not exist in the worker's consciousness, but rather acts upon him through the machine as an alien power, as the power of the machine itself... The production process has ceased to be a labour process in the sense of a process dominated by labour as its governing unity.

- Marx (cited in Leiss, 1990: 45-6)

Our age is not a technological age because it is the age of the machine; it is an age of the machine because it is the technological age.

-Heidegger

\subsection{Introduction}

The purpose of this chapter is not to argue that Harvey's meticulous examination of the relation between capital and technology is incorrect, rather I seek to move beyond this question. By employing the theory of technology developed in Chapter 2, I intend on showing that it is the world as technopresence that has allowed capitalists to appropriate 
technology the way they have and thus has already laid the ground for the unfolding of various accumulation strategies that have been brilliantly illustrated by Harvey. Therefore, what will be considered here is the tension between capitalism and technology as world producing forces.

There are two main arguments in Harvey's writings that will be the focus of investigation in this chapter. First, Harvey's insistence on reducing all relationships to modes of production and labour processes will be examined in light of the world as technopresence. By employing a theory of technology, it will be shown that Harvey's ideas can still hold, however, by further clarifying what is grounding such theory, technology will begin to take on a much more significant part in historical materialism (capitalism as a vehicle for the ordered unfolding of the technological age). More precisely, the world within which capitalism has thrived will be shown to be already ready-at-hand, set-out-before us to be used or driven in certain directions.

Second, Harvey's conception of space-time compression, and the resultant 'shrinking world' as space is annihilated through time, will be called into question. I suggest that this is an incomplete thought. In fact it would seem as though the world is actually expanding, which would overturn Harvey's interpretation, or at the very least make it a paradoxical phenomenon. Which 'world' is Harvey referring to? All indications are that he is pointing to the world which is the modern representational world usually thought as the technological-industrial-rational world. This world, however, was created through the spatial expansion of western 'modern' representational ordering, to the point now where every corner of the globe has been gathered in (just look at a political world map, or satellite photo). How then can 'the world' be said to be shrinking? 
By focussing on these two prominent themes in Harvey's writings, I intend to

1) constrain historical materialism to the level of an intricately detailed description of a component of modernity's unfolding, which through further clarification can be seen to be a manifestation of and vehicle for the world as technopresence; and 2) to explore further the flip side of Harvey's space-time compression, again examining how this relates to the production of the world as technopresence.

\subsection{Locating Technology in a Marxian Analysis}

In The Limits to Capital, Harvey (1982) opens his chapter on "Technological Change, the Labour Process and the Value Composition of Capital" with a quote from Capital.

Technology discloses man's mode of dealing with Nature, the process of production by which he sustains his life, and thereby also lays bare the mode of formation of his social relations and of the mental conceptions that flow from them. (Marx, cited in Harvey 1982, p. 98)

Harvey continues by arguing that Marx is often misinterpreted as being a technological determinist, stating quite clearly from the outset that, "he did not regard technological change as the moving force of history," (Harvey 1982, p. 98). This seems evident from the above quote, however, as has been shown earlier (Chapter 2) it is not any specific technological change that drives history, rather history itself is a product of society when the world can be grasped or conceived of as 'picture'. The following will, therefore, focus on the location of technology in Marxian analysis and subsequently will 
argue that capitalism has been one of the primary vehicles for expanding the world as technopresence.

Upon closer inspection, the quote by Marx above seems to be pointing to a very similar notion to that raised by Heidegger. It could be argued that by stating that 'technology discloses man's mode of dealing with Nature', Marx is pointing to a mode of revealing. So then, Marx could be interpreted as pointing to that realm which lies within the world-disclosing horizon of technology. Unfortunately though, Marx and Harvey seem to be most concerned with what follows, "the process of production by which he sustains life." From this point forward, technology appears only as that which is the means to specific ends determined and directed by capital, where, "technology is a means of dominating, appropriating, or reproducing nature to meet the needs of capital," (Kirsch, 1995). However, Harvey (1982) goes on to say that, "the task is then to penetrate beneath this surface appearance and understand why particular labour processes take on the specific technological forms they do," (p.99). In this, Harvey is absolutely correct, but as with most historical materialists they only extend this penetration beneath the surface so far, and as a result they consequently miss the potential for examining the deeper relationships on which it appears they base their analyses. The world as technopresence is precisely one of these deeper relationships.

To extend this argument further, one must begin with an understanding of how things appear in the world. As I have suggested in Chapter 2, the question becomes one of what forms the metaphysical basis for the appearance of things in the world. Marx states that: 
Men do not in any way begin by finding themselves in a theoretical relationship to the things of the external world. Like every animal, they begin by eating, drinking, etc. That is, not by finding themselves in a relationship but by behaving actively, gaining possession of certain things in the external world by their actions, thus satisfying their needs. (They thus begin by production.)

(Marx, cited in Braun and Castree, 1998: 16)

However, Braun and Castree go on to say that, beyond the fundamental basics necessary for life, "this tells us little about how 'needs' become defined, or, for that matter, what objects are taken up to meet 'needs', or even how this is organised socially," (Braun and Castree, 1998: 16). It is precisely into this gap in understanding that the concept of the world as technopresence becomes useful. It begins by asking what allows things to appear in the world so that they are initially ready-at-hand for an appropriation by modes of production. Historical materialism as employed by Harvey brilliantly analyses the process of technological change through the development of capitalist modes of production. However, Harvey seems to get lost in the idea that technological change belongs entirely within the dialectical relationship between the labour process and modes of production. As such, what is written out of Harvey's historico-geographico materialism, from the outset, is any discussion about the 'how' things come to lend themselves to the process of commodification. Locating technology within Marxian analysis, then, will be a two-pronged approach. First, it examines how Harvey has used technological change to explain the inherent contradictions of capitalist development, and second, it will simultaneously place the world as technopresence as that understanding which first frees things to be appropriated into the unfolding of capitalism. Furthermore, 
capitalism remains well suited for the reproduction of a technological orientation towards entities encountered in the world.

Harvey continues his discussion by stating that the, "identification of 'technology" with the 'forces of production' is erroneous," where, "technology is [in fact] the material form of the labour process through which the underlying forces and relations of production are expressed," (p. 100). By this point, technology has already been narrowed down to a purely instrumental and material phenomenon. The initial quote regarding 'technology as that which discloses man's mode of dealing with nature' has thus been rendered meaningful only through an analysis of specific technologies, and this includes the management and organisational practices inherent in the production process. For Harvey, then, any inquiry into technology is only useful in so far as it discloses the, "nature of productive forces and the social relations embedded within the capitalist mode of production," (p. 100). But what then are we to make of the "mental conceptions that flow from them'?

Harvey suggests that, "mental conceptions of the world can become a 'material force' in a double sense: they become 'objectified' in material objects and materialised in actual production processes. The activity of production therefore incorporates a certain knowledge of the world - knowledge that is also a social product," (p. 101). Furthermore, Harvey insists that, "the actual technology of the labour process is shaped by historical and social processes and necessarily reflects the social relationships between human beings as they combine and co-operate in the fundamental tasks of production," (p. 101). It appears as though all social relations are simultaneously a product of modes of production and produce further changes in modes of production, which in turn change 
social relations. This argument, that of dialectical relationships, would certainly appear to be self-evident. However, the questions begin to arise with the initial point of departure for such an understanding. Harvey furthers this argument in his subsequent texts, coming to rest on an intensive investigation of the contradictions between modes of production and modes of representation. At no point, however, does he abandon the original position that he sets up in The Limits to Capital, as this consistently forms the basis for his further examination of shifts in modes of representation that arise from modernity to 'postmodernity', a shift which he feels does not break significantly with the modern history of capitalism (Harvey, 1989; Harvey, 1996).

Following in the materialist tradition, Harvey appears to accept that the 'actual relations of life', that is in the mixing of labour with nature, are the ontological beginnings of historical and social processes that shape the employment of specific technologies. What is disconcerting in these arguments is that nature is initially present in such a way that is unproblematic. This brings back the question, of how it is things appear in the world in the first place, so that they are accessible for these modes of production which employ specific technologies. But Harvey has stated that 'the activity of production incorporates a certain knowledge of the world'. Although, the capitalist mode of production might be indicative of specific relationships, social and natural, it still remains to be seen what that certain knowledge of the world is that has allowed modern capitalism to proliferate the way it has. By introducing the world as technopresence here, one begins to see how it is that things appear in the world ready-athand, and will consequently easily lend themselves to appropriation by capitalist modes of production. The shift to a modern mode of disclosing the world, through technological 
enframing, already presents things in the world in a manner, that Heidegger has called quite appropriately for this discussion, 'standing-reserve'.

For Harvey, then, modes of production form the basis for disclosing the world in particular ways. Technology then shows up, in a purely instrumental understanding, as the material expression of the social relationships that arise out of a continually evolving relationship to nature. The spread of capitalism around the globe, therefore, is only possible through the proliferation of distinctly capitalist modes of production. However, technology presented in this manner is thought of as instrumentality, which is inherently tied to means and ends, to utility. This is precisely the relationship to technology that Heidegger warns perpetuates the current technologically oriented society that continues to alienate humans from nature, as well as from the products of their labour (Heidegger, 1977). As this also seems to be a concern for Marxists, and one that has certainly not been overcome, it might prove useful to remove technology from its capitalist bonds, and search for that freer relationship to technology that Heidegger proposes can come about within the world-disclosing horizon of technology.

\subsection{Rescuing Technology from Capital}

The argument that the world is disclosed through the continual evolution of capitalist modes of production, along with the resulting technological change and shifting social relations, initially appears to be a rather convincing discourse. However, as was shown above, this theory provides little in the way of how and why certain things in the 
world are originally available for appropriation by this system. If this system is born out of 'the actual relations of life', which I presume to mean at the most basic level food, shelter, clothing, then how has it come to be that 'things' such as genes, culture, and intellectual property have recently been commodified. These are the inevitable questions that arise.

As Harvey (1982) puts it:

The insatiable quest on the part of capitalists to appropriate surplus value impels perpetual revolutions in the productive forces. But these revolutions create conditions that are inconsistent with the further accumulation of capital and the reproduction of class relations. This means that the capitalist system is inherently unstable and crisis-prone. Though each crisis may be resolved through a radical restructuring of productive forces and social relations, the underlying source of conflict is never eliminated. New contradictions arise which generate ever more general forms of crisis. The only ultimate resolution to the contradictions lies in the elimination of their source, in the creation of fundamentally new social relationships - those of socialism. (p. 103)

There are several points that raise concern in this passage, but I will concentrate on the final point. It appears as though, Harvey sees the production of the world as the result of the tensions that have been described above. However, by stating that the elimination of these contradictions can only arise out of the "creation of fundamentally new social relationships through socialism', Harvey has not addressed the underlying issue of 'industrialism'. As such, socialism does not necessarily constitute an entirely new set of social relationships. By thinking the world as technopresence here, one can begin to see that if technological entities are allowed into the social world, as they were implied to be with Latour's 'missing masses', then it is not simply in a shift in social relations (thought human) that will lead to an entirely new set of relationships. Technology, as a major 
component of the 'social world', must be considered beyond its mere presence for human use, or in this case, capitalist use. For Heidegger, socialism and capitalism were simply flip sides of the same coin, different expressions of the same technical system, and it was this view that led him to the reactionary political stance that initially aligned him with the National Socialist Party in the 1930s (Harvey, 1996; Harvey, 1989; Zimmerman, 1990). Heidegger felt that initially the National Socialist Party offered a way out of the technological modernity that was evident in the, "industrial capitalism and industrial communism," that surrounded Germany in the 1930s, exemplified by the United States to the West and the Soviet Union to the East (Zimmerman, 1990: xvii). By 1936, Heidegger had disassociated himself with the party, as it became increasingly clear that the Nazis were not disengaging with a technological relationship to the land, but rather, were seeking a superior technological efficiency through which they could expand their interests (Zimmerman, 1990). That is, technology in Nazi Germany was not moving towards the kind of renewed relationship with the world that Heidegger was seeking, and in fact, as Germany's war machine and political spectacles began to take hold, it was clear that the modern technological ideals of rationality and efficiency were leading the country in precisely the direction Heidegger had sought to overcome.

To illustrate further, early Nazi posters bear a striking resemblance to the sentiments held by the current anti-globalisation movement, a movement that also seems concerned with many of the issues addressed by Harvey.

Our call goes out to you who earn your bread through honest work. If you don't want your children, and your children's children, to be damned for all eternity as slaves of world capitalism, if you don't want to be made into the protectors of Stock Exchange bandits and other blood suckers by your treacherous leaders, if you are on the contrary filled with a fanatical 
will of freedom, then join the ranks of [the] National Socialist German Workers Party. (Nazi poster circa 1926, cited in Zimmerman, 1990: p. 39)

The German farmer stands in between two great dangers today: The one danger is the American economic system- Big Capitalism! It means "world economic crisis"; it means "eternal interest slavery"; ... it enslaves man under the slogans of progress, technology, rationalisation, standardisation, etc.; ... it wants to make the world into a giant trust; it puts the machine over man; it annihilates the independent earth-rooted farmer...

The other danger is the Marxist system of BOLSHEVISM. It knows only the State economy; ... it brings in the controlled economy; it doesn't just annihilate the self-sufficient farmer economically- it roots him out...; it brings the rule of the tractor; it nationalises the land and creates mammoth factory-farms... (Nazi election campaign poster, cited in Zimmerman, 1990: p. 42).

Aside from the retrospective horror that any connection to the Nazis invokes, these slogans point to the astonishing similarities between current discontent with the world system, and those that concerned Heidegger at the time. In a some what eerie way, they also parallel many of the 'post' critiques in contemporary academic literature, especially regarding challenges to 'progress, technology, rationalisation, and standardisation' (I am aware that this thesis is also implicated here). Most significantly, here, they illustrate at the very least the problem with Harvey's assumption about socialism providing an entirely new set of social relations. However, by taking into account the world as technopresence, one begins to see that the underlying relationship to entities encountered in the world will not be significantly altered through a switch to socialist ideals. The question then becomes one of not just capitalist modes of production, but rather, that which has produced the rampant industrialism indicative of modern society, whether it is seen on the left or the right of the political spectrum. For as far as I can discern, the question that pertains to the differences between capitalism and socialism, generally 
reflects the matter of ownership and control, and will not necessarily produce the altered relationship to nature that Harvey begins to search for in Justice, Nature and the Geography of Difference (1996), and Spaces of Hope (2000). Harvey's remarkable epilogue to Spaces of Hope, spells out an alternative future that manages to suggest many of the possibilities that Harvey's view of new social relations entail. In fact he goes so far as to pick up on the technological and ecological themes that are so essential to this thesis. However, as much of the focus of his utopian vision is predicated on the abolishment of property (as well as possession), the treatment of technology as something essentially different than a mere tool is still missing. In spite of the role Harvey attributes to technology within the downfall of the modern world, with the rise of his utopian world, it seems that technology still shows up in a similar manner, albeit with an ecological and social component that is clearly lacking in today's society. Yet, he still does not seem to count it within the greater transformation of the social world. Humans and technology are still held apart, and its transforming role seems to be missing, as the new society simply destroys undesirable technologies and appropriate more desirable ones (always as tools).

Throughout Harvey's works, technology is consistently positioned in its relationship to capitalist modes of production, as was discussed above and treated primarily as instrument. I have tried to show here, with a demonstration of the inherent connections between socialism and capitalism under their unifying classification of 'industrialism', that in fact there is something beyond simply capitalist modes of production that has led to the continued unfolding of the modern age. I have also suggested that thinking the world as technopresence can bring to the fore, those 
underlying relationships that seem to escape Harvey's historical materialism. Therefore, the search for a more appropriate relationship to 'nature' will not arise by positioning ecological concerns within the realm of a specific political platform. Instead, what is required is the ascendancy of ecological concerns within all political parties, and in order for this to be the case, the way in which the world is primarily disclosed must form the basis for any significant change.

Thus, the basis of Political Ecology, various Green Parties, or Harvey's insertion of environmental concerns into the call for social change (through socialism) will inevitably be stuck with the politicising of issues that are in desperate need of moving beyond their current position as distinctly political issues. So long as the 'environment' remains something that is political, there will always be the unnecessary choice of either/or. The environment will constantly be placed in opposition to an alternative choice and will consequently continue to be something that is either opted for in a particular situation, or denied in others. This can certainly be seen within the North American landscape, with its mix of industrial parks and national parks. Latour (1998), in To Modernise or Ecologise? That is the Question, sees precisely this problem. He draws similarities to the hygiene movement that arose in the $19^{\text {th }}$ century as a result of the 'discovery' of microbes. In doing so, he quite cleverly points out that there were no 'hygienist parties', and that this movement simply became a routine backdrop for all political parties, as well as all citizens (Latour, 1998). However, in order for this to happen to produce an ecological society, it would seem as though the changes must arise at a level beyond the specifics of politics, economy, and government and therefore must be positioned at the level of world-disclosing horizons. As such, if the world as 
technopresence has produced the ecological concerns that are present in Harvey's later works, then it follows that technology must be freed from its bonded relationship to capitalism and thought beyond the political solutions that necessarily results. In short, technology has to be rescued from its position of instrumentality within capitalism. It is only then, that one can begin to understand how it is that things appear in the modern world and how it can be that that can change.

\subsection{Space-Time Compression: Is the 'World' really shrinking?}

Harvey's shift to an examination of the relationships between modes of production and modes of representation are found in his employment of the concept of time-space compression in both The Condition of Postmodernity (1989) and Justice, Nature and the Geography of Difference (1996). It is here that Harvey turns his attention to the metaphor of the 'shrinking world', as he borrows from Marx's conception of the 'annihilation of space through time'. However, several questions need to be addressed here. First, of which world is Harvey imagining? Second, is the overcoming of spatial barriers by capital, through technological innovations, shrinking the world, or simply distances (measured in speeds)? And finally, whose world is shrinking, and for whom is it beneficial?

To address these questions, one must begin to think about what the metaphor is implying. The first question inevitably must ask which world is it that we are to imagine as getting smaller. The tension between capitalist modes of production and the world as technopresence, as world-disclosing forces, come to the fore through the metaphor of a 'shrinking world'. Harvey tends to subscribe to the historical materialist conception that 
the, "transition from feudalism to capitalism entailed a fundamental redefinition of concepts of space and time which then served to reorder the world according to quite new social principles," (Harvey, 1996: p. 239). However, this seems to assume that the shifting conceptions of the world, as were demonstrated by, "the Cartesian-Newtonian conceptions of absolute space and time," were also derived from shifts in the economic processes of society (Harvey, 1996: p. 238). In spite of addressing the idea of the rise in the modern mode of disclosing, as "[providing] unambiguous means for establishing identities (be it of individuals, things, properties, collectivities such as nation states as territorial units, and the like)," Harvey seems to pay little heed to the implications of writing 'the chicken or the egg' dilemma into his geography (Harvey, 1996: p. 239).

Harvey, as discussed above, takes great care to emphasise the significance of technological change within the unfolding of the world and this is not lost when his attentions shift to modes of representation. However, this is still seen as being inherently tied to capitalist modes of production. As such, Harvey (1989) makes the observation that,

Innovations dedicated to the removal of spatial barriers ... [have] been of immense significance in the history of capitalism, turning that history into a very geographical affair - the railroad and the telegraph, the automobile, radio and telephone, the jet aircraft and television, and the recent telecommunications revolution are cases in point.

But here, too, capitalism encounters multiple contradictions. Spatial barriers can be reduced only through the production of particular spaces. (p. 232)

Again, one is left wondering in what kind of world do these 'things' appear, and what are these particular spaces. Is the altering of space through these particular technologies, where it appears that distance is collapsing under the increasingly efficient (and it might 
be added, economically feasible) employment of specific technologies, leading to a shrinking world. For Kirsch (1995), it is not, and he quite correctly uses the notion of technology, drawing on Lefebvre's production of space, to show that although technological change is certainly altering space-time configurations, the metaphor of a 'shrinking world' is not necessarily an appropriate image. "Technology, then, is a process between society and (a socially externalized) nature, even as material technological practices serve to alter the very relations of space and time to human experience - the boundaries of 'nature' within which meaning is constructed," (Kirsch, 1995: p. 535, italics original). Although Kirsch's (1995) critique goes a long way into re-inserting the significance of technology in conceptions of space-time, he appears to get tied up in asserting that space-time is being altered through technology, but fails to think through his position that 'technology is a process between society and nature'. Instead, he seems to focus on the 'networks' of technological development, their employment, and the social processes inherent in 'Actor Network Theory'. As such, he draws heavily from Latour, Haraway, and Law, to supplant technological networks into Lefebvre's 'production of space'. However, he does manage to offer a couple of salient points with regards to Harvey's metaphor.

In reference to the spread of specific technologies, particularly those of transportation and communications technologies, Kirsch makes the astute observation that there is a paradoxical relationship between annihilating spaces and the creation of new spaces. Kirsch (1995) writes, in reference to the proliferation of the railroad in the $19^{\text {th }}$ century that, "as much as the railroad annihilated space (read: friction of distance), so too did it create spaces, making heretofore isolated lands accessible to more rapid and 
expansive networks of exchange. So while 'the annihilation of space and time' reflects a keen awareness of the elasticity of these dimensions, it also served to mystify these changes by shrouding them in an ontology of scientific and technological triumphalism," (Kirsch, 1995: p. 542, italics original). Following from this, it would be useful to think of the world as technopresence. It is through a technological 'enframing' that the world is first made into a series of objects which stand over against the human knowing subject. As such, space too becomes produced as something that is 'objectified'. For Kirsch, "to articulate more fully the role of technology... we need also to pursue the connection between the production of space and the production of objects, which is to say, the technics through which social actors or groups strive to produce space like an object: engineered, reproducible, and controllable," (Kirsch, 1995: p.548, italics original). However, after this point Kirsch's argument fails to go that one step further, which is to ask what kind of world harbours the unfolding of such processes. This is precisely where the world as technopresence needs to enter the discussion.

By thinking the world as technopresence, Harvey's metaphor of a 'shrinking world' becomes problematic. Harvey invokes the image of an already complete world to begin his thinking on the modes of representation that arise from the overcoming of spatial barriers (Harvey, 1989). However, the world was not standing by ready to be represented as whole without there first being a conceptual gathering of every space into a representable whole, or rather a 'world picture'. It appears that Harvey has taken as his point of departure a world that lay ready for 'uptake' into the systematic technological grid, and consequently has written out the initial, often violent, transformation of the multiple worlds that existed into a singular representable whole. This is a strange 
position, as Harvey has been consistently concerned about the 'other' in the resulting uneven patterns of development through capitalist expansion (Harvey, 1996; Harvey, 1989). In effect then, the diffusion of a technological understanding of 'things', in which space had also been incorporated, had to precede that of capitalist expansion, where space was something to be overcome. In short the world already has to be technopresent, there as an object, in order for it to be said that it is 'shrinking'. Likewise, time and space must also be conceived of in a particular way to support such a metaphor, in that they are necessarily measured by the technological capacity for speed of communication or transport. Therefore, thinking the world as technopresence has once again been shown to ground Harvey's theories and simultaneously hold them within its scope of concern.

Technology then, can be seen as that which offers up a world for 'the taking', and capitalism has certainly been the primary vehicle driving it in specific directions. Yet, as far as I can discern, Watson and Crick were not thinking about the potential for capital accumulation by stretching the scientific inquiry to the microbiological scale of DNA, although there is certainly a growing market for such 'things' now. How then does historical materialism explain the appearance of such phenomena? Perhaps, it is the sheer range and scale of a technological understanding of things in the world that has continually been expanding. Again, this can be seen in the diverse commodification of specific genes to the 'space' (satellite) speculation on mineral deposits. Satellite photos and genes seem to be a long way from the 'actual relations of life'. As well, as mentioned above, although the discovery of 'microbes' by Pasteur in $19^{\text {th }}$ century France had a profound effect on social relations, this can certainly not be entirely contained within 
capitalist modes of production, the very ones that Harvey presents as that which are producing the world.

Furthermore, with the technological connections, through financial markets, internationalism (the state as technical organisation), communications, and transportation the 'friction of distance' has certainly been reduced, but Harvey locates 'the shrinking world' in the experience of everyday life (Harvey, 1989). However, it is precisely at the scale of everyday experience that it should be claimed that the world has in fact expanded. As Harvey continually focuses on the 'fetishism of commodities', that is that the spatial locations and labour practices that are inherent in the production of any commodity remain hidden in its 'presence' and 'value' (thought money), it is remarkable that he takes little notice of the spatial expansion that opens up through a technological connecting of the globe. Through this technological connection of the globe, the world of everyday experience has expanded dramatically. Suddenly, issues, things, and people that would have previously never entered our scope of concern appear daily in our world of experience. With the continual advancement (measured by efficiency of speed) of transportation technologies, the geographic area of our daily experience has significantly expanded. One hundred years ago, a person's work and home might have been located within a few kilometre radius. Where today, a person's work might be located up to 100 kms from their home, or perhaps if measured in time, over an hour commute. Moving on to communications technologies, the distant occurrences that 150 years ago would have only possibly shown up months later, now appear instantly. This can be witnessed through the proliferation of 24 hour news stations and a 24 hour weather network (which might account for the perception that extreme weather events are increasing). 
Furthermore, the instantaneous communications links allow local reporters to cover global issues. It might be argued that these are simply technological representations of some distant reality. But that is precisely the point.

By Justice, Nature and the Geography of Difference, Harvey (1996) has begun to take Heidegger's philosophy seriously and in fact tries to reconcile the differences between Heidegger and Marx. However, Harvey still insists that although, "there is certainly enough credibility in the Heideggerian argument to make it worthy of careful consideration... there are strong grounds for rejecting it in its original guise," (Harvey, 1996: p. 302). Perhaps, part of this rejection results from Harvey's failure to distinguish between Early Heidegger and Late Heidegger, a distinction that most Heideggerian scholars make (Zimmerman, 1990). As such, Harvey seems to focus almost exclusively on Heidegger's notion of place as the locus of Being, which is derived from Early Heidegger's engagement with the existential analytic of the spatiality of Dasein (Harvey, 1996; Zimmerman, 1990; Heidegger, 1962). Following from this locating of Heidegger, Harvey focuses his efforts on Heidegger as a phenomenologist, in line with what is considered Early Heidegger (although the books he references in JNGD are indicative of Late Heidegger). Indeed it becomes clear that Harvey misses the potential that Late Heidegger can offer to the discipline of geography, as he is consistently failing to surface in Harvey's work. Although a coherent theme runs through Heidegger's work from Early to Late, it is explicitly through his later works that he begins to leave the existential experience of being-in-the-world to focus on the 'world' itself, specifically the modern world. It is through this line of questioning technology and modernity that Heidegger first begins his metaphysical history of the West that subsequently inspired many of the 'post' 
writers in the $20^{\text {th }}$ century. Harvey seems to recognise this only as an afterthought when, in trying to reconcile Marx and Heidegger, he states that the root of the problem is, "specified as peculiarly capitalist by Marx and modernist - i.e., both capitalist and socialist - by Heidegger," (Harvey, 1996: p. 315). In that Harvey apparently misses this development in Heidegger's thought, it is not surprising that his critique narrowly focuses on the conception of place and Being. It is through this discourse that Harvey sees fit to reject Heidegger as he assumes that because Heidegger's reaction, to the universal modernising threat to 'place and Being', led to his initial association with the National Socialist Party, that all invocations of place that hold a particular sense of 'dwelling' must give rise to an exclusionary form of nationalism (Harvey, 1989). As such Harvey has difficulty in employing the concept of 'dwelling' that effectively acts as a bridge between Early and Late Heidegger.

In addition, it appears as though Harvey seems to read Heidegger with a particularly Marxist slant. In interpreting the following passage, Harvey claims that, "Heidegger recognizes that the achieved shifts in space relations are a product of commodification and market exchange," (Harvey, 1996: p. 300). The passage reads as follows:

The object-character of technological dominion spreads itself over the earth ever more quickly, ruthlessly, and completely. Not only does it establish all things as producible in the process of production; it also delivers the products of production by means of the market. In self-assertive production, the humanness of man and the thingness of things dissolve into the calculated market value of a market which not only spans the whole earth as a world market, but also, as the will to will, trades in the nature of Being and thus subjects all beings to the trade of a calculation that dominates most tenaciously in those areas where there is no need of numbers. (Heidegger cited in Harvey, 1996: p. 300) 
When Heidegger is speaking here of the establishment of 'things as producible in the process of production' and 'self-assertive production', he is certainly not speaking of simply the capitalist system. He is in fact, as Harvey conveniently recognises elsewhere, speaking of the 'essence' of modernity (see above). Heidegger makes no objections to the point that capitalism is a manifestation of the technological unfolding of the world, yet Harvey seems to miss the 'it' (technology) that peppers the above passage. It is 'technology', or rather the 'essence of technology', that first establishes things as producible. It becomes increasingly apparent that Harvey has not left behind his conception of technology that situates it as the material manifestation of the social relations inherent in capitalist modes of production. As such, Harvey seemingly does not read this passage with Heidegger's conception of technology in mind and consequently misses what it is Heidegger is implying. Perhaps, this is why Harvey chose to ignore the line that appears two paragraphs further in the text he cites from Poetry, Language, Thought (Heidegger, 1971). "Self-assertive man," Heidegger continues, "whether or not he knows and wills it as an individual, is the functionary of technology," (Heidegger, 1971: p. 113). This point never seems to be either refuted or acknowledged in Harvey's works. This becomes evident in the questions Harvey asks of Heidegger's argument, such as, "what might the conditions of 'dwelling' be in a highly industrialised, modernist, and capitalist world," (Harvey, 1996: p. 301). Although, Heidegger certainly does not offer any ready-made solutions, his in depth discussion about how the modern world is disclosed through a technological mode of revealing, and his insistence on bringing ourselves into a freer relation with world disclosing horizons, seems to fail to register as significant within Harvey's reading of Heidegger. As a consequence Harvey continues to 
struggle with creating entirely new sets of social relations (to nature) out of the very ground that has grown the current set.

Although, I may have seemingly digressed from the discussion of space-time compression, it was a necessary detour. For the world Harvey uses as his point of departure is precisely the world that begins Heidegger's questioning. It is therefore imperative for an understanding of how the world is represented. Harvey does not permit Late Heidegger to surface in his works, and when he does manage to poke through he is read as being a misguided Marxist. Consequently, Heidegger is consistently pigeonholed into the position of a phenomenologist, who is apparently incapable of understanding, "the processes of commodity production that put our global breakfast upon our individual tables," (Harvey, 1996: p.313). As Harvey only focuses on the continual overcoming of spatial barriers through the evolution of capitalism, technology is thus seen as merely a means by which distances are reduced creating the spectre of a 'shrinking world'. However, by reading Heidegger's conception of 'technology' back into the discussion, he is not only capable of understanding the 'fetishism of commodities', but seeks to move beyond the surface appearance of reality, and look further into what kind of world allows for 'things' to become commodities in the first place. As such, 'the object-character of technological dominion' must first gather in everything and it is precisely through this process that 'the world' can be said to be expanding, as the world as technopresence, with its associated ordering of reality, rises as the sole representation of the real. 


\subsection{The World beyond Capitalism}

Having arrived at this point, it can be seen that there is considerable tension between an historical materialist conception of how the world is disclosed contrasted against technology as a world-disclosing horizon, and the resulting world as technopresence. Therefore, an assessment of the two together would be a useful exercise. Although, Harvey's elaboration of technological change in capitalist modes of production and the shifting modes of representation that result have been carefully examined in his work, by re-thinking technology beyond its instrumental application some of the difficulties with the resolution he seeks in creating an entirely new set of social relations can be brought to light.

For Harvey technology resides in the material expression of the social practices inherent in the continuing resolution of the contradictions that form the very basis of an unstable capitalist system. Following from this line of reasoning, Harvey sets the shift from feudalism to capitalism in $17^{\text {th }}$ century Europe as the beginning of the modern age. As a consequence the modern world is a product of the unfolding of the continual struggle between the labour process and the accumulation of capital, and the crises that arise from the need to accumulate capital in a spatial location and the need to overcome spatial barriers to further that accumulation. The ultimate goal is to disrupt the crisisresolution cycle of the capitalist system by creating an entirely new set of social relationships and practices through a shift to socialism.

Following from Heidegger's examination of technology as that which has sent the modern age into its unfolding, the world as technopresence begins with a very different premise. Locating the beginning of the modern age at around the same time, the $17^{\text {th }}$ 
century, and with many of the same characters (e.g. Descartes), this theory proposes that it was primarily the Scientific Revolution, that shifted the collective understanding of 'things' in the world and has thus formed the basis for the modern worldview. For this theory, technology is not to be conceived of as merely an instrument, but rather as a way of revealing 'things' in the world so that they come into appearance as 'things' to be used, as objects. In order for a significant change to arise, the world as technopresence must be replaced as the only legitimate access to things in the world, as that which allows for a perpetuation and proliferation of an 'industrialism' that continues to marginalise other ways of revealing and consequently leads to the further alienation from and externalisation of the natural world.

Although, both theories are plausible, there is a significant difference between them, one that becomes more evident as one looks to how things can change. For Harvey, with technology residing in capitalist modes of production, it is not clear how a different relationship to 'nature' would unfold with a flip to socialism, which is itself, another form of 'industrialism'. However, it has the world as technopresence suggests that it is not just a change in social relations that will alter the current course of the world, but rather a shift in social relations that take technology as forming part of the social, alongside nature, humans, and other 'things' that make up the world. Furthermore, the inherent political nature of his discourse has the unfortunate result of 'politicising' issues that need to move beyond any attachment to a singular location on the political spectrum. Uneven social development, social justice, and the environment would certainly fair better if they were not tagged to a particular political party or political movement. For all of Harvey's manipulations of Marx's work, the promise of resolving these issues within the historical 
materialist framework seems to be problematic. However, thinking technology as a world-disclosing horizon offers a distinctly alternative view to how things can change. First, the world as technopresence can easily hold all of Harvey's theories about technological change and capitalist modes of production. It does, however, provide an explanation for why 'things' have been so easily appropriated by the continual growth of the capitalist system, as it presents them as being present in a manner that enframes them as entities that are always already ready-at-hand, precisely in that they are there to be used. The value of 'things', thus arises from their ranking in the ordered reality that results from the revealing of the world as technopresence. Things therefore, are assessed by their tractability of 'fitting' into the world market system, and by their relative ease of 'uptake' into a systematic technological framework that stretches over the globe.

Following from the above arguments it seems as though there are several difficulties with Harvey's conception of the world, and particularly with where he sees the potential for change. Thinking the world as technopresence, therefore, offers a way beyond the boundaries of capital and simultaneously holds historical materialism within its scope of concern. However, as has been shown, it is not just capitalist modes of production that produce the modern world and one must begin to think beyond these relationships to assess the possibilities for change. Thinking technology as a worlddisclosing horizon manages to sidestep the awkward distinction between socialist and capitalist industrialism. As such, it presents a possibility for change that will not inherently politicise issues that need to move beyond their current political borders. Such a move looks into how one exists in the world and what type of world is affecting our existence. In that this theory of technology is also linked to the material reality of 
everyday' life, albeit with a specific focus on the technological mediation of experience, Harvey's historical-geographical materialism can still be a useful way of thinking about the resulting spaces that arise from specific material practices. However, by grounding Harvey's analysis in the world as technopresence, some of the problems that have consistently plagued Marxism, particularly in its vision of creating new sets of social relations, can be thought through in a manner that opens up opportunities for change that are removed from the necessity of a full-scale political revolution that has yet to show signs of appearing. 


\section{Chapter Five \\ Thinking Technology in Derek Gregory's Geographical Imaginations}

\subsection{Introduction}

Derek Gregory opens his Geographical Imaginations (1994) with a quote from

Saint-Exupéry's Wind, Sand, and Stars, speaking of the 'geography lesson' and the geography typically written out by the geographers.

But what a strange lesson in geography I was given! Guillaumet did not teach Spain to me, he made the country my friend... The details that we drew up from oblivion, from their inconceivable remoteness, no geographer had been concerned to explore. Because it washed the banks of great cities, the Ebro River was of interest to map-makers. But what had they to do with that brook running secretly through the water-weeds to the west of Motril, that brook nourishing a mere score or two of flowers?

"Careful of that brook: it breaks up the whole field. Mark it on your map." Ah, I was to remember the serpent in the grass near Motril!... And those thirty valorous sheep ready to charge me on the slope of a hill!

Little by little, under the lamp, the Spain of my map became a sort of fairyland. The crosses I marked to indicate safety zones and traps were so many buoys and beacons. I charted the farmer, the thirty sheep, the brook. And, exactly where she stood, I set a buoy to mark the shepherdess forgotten by the geographers. (Saint-Exupéry, cited in Gregory, 1994: 3) 
I have cited the passage in full here, because it significantly sets the tone for what follows in Gregory's work. It would appear that Gregory's position of writing the 'forgotten' geographies back into Geography would initially be capable of discussing technology within the Geographical Imaginations that he sets up for a re-incorporation into the discipline. Furthermore, as one begins to read through the book one finds continual references to technology, and even to Heidegger, so it would initially appear that at least there is one geographer who is beginning to make the connections between geography and technology. However, as Gregory's argument unfolds, it becomes painfully clear that this marriage is not made, and further, that any inklings towards such a conception are typically written out within the next few paragraphs.

For the first part of the text, the space has been opened, the characters have been set, and the technology is present, yet it appears that Gregory too gets lost in his own creative manuscript and that the play that he is orchestrating somehow requires a fourth act that never arrives. As one progresses through his work, reading as he brilliantly weaves histories, theories, and geographies into a rich tapestry of the unfolding of the world, it becomes increasingly disconcerting and clear that for all his writing back 'in', he has unfortunately written himself 'out'. This is not to say that he doesn't go through a painstaking effort to explain the significance of his positionality and the context from which the book has sprung (which is well articulated in the preface), but rather it becomes extraordinarily difficult to determine precisely where he is situated. As Harvey so eloquently puts it, "in his laudable concern to be fair, Gregory at times distances himself so far, politically and intellectually, from what is being said that it is hard to 
locate not only where he stands on certain crucial issues but what he himself is trying to do," (Harvey, 1995: p. 161).

However, Harvey misses what Gregory views as, "a very vital political service to geographers by producing a book that depoliticises their (our) work," (Gregory, 1995: 178). It is precisely this precarious position that makes Gregory so difficult to critique. Although, critiquing Gregory is difficult it is not impossible.

What will be extracted from this often frenzied text will be the tracing of the extent to which Gregory considers the modern disclosure of the world throughout his discussions. As will be shown, although he begins with a considerably detailed account of the early rise of the modern world, this often gets lost in his further investigations and at times disappears altogether. It will be through an examination of Gregory's own set up of the world, which often invokes an image of a specific understanding of modernity, that the world as technopresence will be seen to be a significant force within his Geographical Imaginations.

\subsection{Origins of 'The World'}

Following from the opening of the text, the first chapter, Geography and the World-as-Exhibition, begins with enormous promise and consequently it is this section that will form the primary focus of this chapter. It would appear from the outset that in Gregory's search for geographical imaginations that he has in fact turned his attention towards the production or disclosure of 'the world'. In this he does an excellent job, but as mentioned above, with the continual invocation of the voices of scholars, philosophers, social theorists, and the like (almost all read through secondary sources) it proves 
difficult to know whether it is Gregory speaking or he is simply offering a stage on which the conversation of a few centuries of writers are allowed to appear, under his authoritative direction of course. Thus, the approach that must be taken is to question Gregory the director, for it is inevitably through his direction that these multiple voices are brought to bear on how the narrative of Geographical Imaginations unfolds.

As stated above, Gregory intriguingly takes as his point of departure the rise of the modern world and modernity more generally. He writes that geographers have been complicit in this process and that his examination will not solely focus on those geographers that are often heralded as the heroes of the discipline's development. Taking, what Livingstone, a geographer concerned with geographers, has said there is a compelling case for, "the importance of geography [in] the construction of modernity during the sixteenth and seventeenth centuries." He continues, "on his reading, the Scientific Revolution of the seventeenth century may have depended, in complex but nonetheless crucial ways, on the voyages of discovery," (Gregory, 1994: 17). Gregory sees that this might in fact be the case, but he quite cleverly points out that the transition to modernity was not so instantaneous and clear-cut as some histories (and geographies for that matter) might have us believe. In fact:

Whatever force it may have had in other directions, geography - like other forms of knowledge in the sixteenth and seventeenth centuries - was also deeply implicated in magic and myth, cosmography shaded indiscriminately into astrology, and the shores of empirical science were still distant, blurred. On this reading, the difference between the sixteenth and the eighteenth centuries turns not so much on the distinction between myth and direct observation as on the different status accorded to information derived from the two. Those 'other' knowledges are absent from the standard histories of geography too, but [the] point is simply that they have no place in the modern discipline at all. (Gregory, 1994: 17, italics original) 
In this passage, one begins to see the opening of Heidegger's technological age, an idea that Gregory takes up in much more detail further on. It is through this beginning that it appears as though Gregory is also concerned about the rise of modernity, and it becomes quite evident that he is certainly resistant to locating it within the historical materialist position that slots everything into the evolution and history of capitalism. He, too, is more concerned with the Scientific Revolution as that which has altered conceptions of reality, which in turn produce the modern ordered reality with which the west is now so familiar.

The similarities between Gregory's account and Heidegger's 'technological age' continue as he introduces Cook into the equation, again drawing on the secondary source of David Stoddart to provide the character voice for Cook in his unfolding drama. As mentioned above, Gregory is looking beyond geography's conventional disciplinary father figures (a term that I'm sure would make him cringe), and consequently intends to write Cook back into geography's history. Although, Gregory obviously would not agree with Stoddart's precise location of, "the transformation of geography into an empirical science [in] 1769," he does believe that Cook as a figure can be, "made to stand for a cluster of overlapping intellectual traditions," (Gregory, 1994: 17). Gregory continues his defence by stating that:

Only in Glacken's Traces on the Rhodian Shore does Cook appear, as he does in Stoddart's account, as the superintendent of 'a scientific undertaking, a harbinger of the nineteenth-century scientific traveling of Humboldt,. Darwin, and the Challenger,' and as the bearer of a discourse that legitimated itself through 'reliability in detail and authenticity.' (p. 18) 
This can certainly be read as the beginnings of the world as technopresence, and brilliantly brings into focus the connection between geography and a technological mode of revealing. By invoking such images, Gregory is intent on showing modern geography's rise out of the empirical field studies that were transforming the natural sciences and the associated field of natural history.

The connection to and implication for thinking the world as technopresence seem to arise only much later in Gregory's account, when he begins to discuss the process of colonisation and its implicit spatial strategies. Although, as I will show, the grounding theory for this does arise in the first chapter, Gregory best describes the implications of the exploratory field studies in his discussion on colonialism and postcolonialism (this is an example of the difficulties in his presentation format for the book). Gregory here states that:

It is impossible to conceive of colonialism or imperialism 'without important philosophical and imaginative processes at work in the production as well as the acquisition, subordination, and settlement of space.' That much should be obvious from geography's own complicity in colonialism, but what has been acknowledged much less often, at least until recently, is the connective imperative between those colonial projects, the production of space and various modalities of powerknowledge. (Gregory, 1994: p. 168)

If one takes the evolution of the world as technopresence into account, the conceptions that were missing in Harvey's writings can certainly follow here. What Gregory is demonstrating is that what must first precede any engagement with other worlds is a methodology that is capable of transforming the unfamiliar into the familiar, which results from stretching a technological mode of revealing over the surface of the Earth so that the world appears to be universally present within a specific ordering of 
reality. Through this it follows that foreign lands and peoples (non-European) can be communicated back to Europe that in a sense completes the European world gaze and simultaneously confirms and legitimises the globalising capacity of the modern worldview to incorporate 'things' rationally within the world.

Following from this, one can begin to see that the themes of the world as technopresence are consistently present within Gregory's text, yet to trace them as such proves to be a much more difficult task. As I have been showing here, Gregory has begun to demonstrate the connections between early explorers and the simultaneous ascendancy of modern science. This picks up on Heidegger's themes to some degree; however, what is conspicuously missing is the connection to Latour's 'missing masses', as Gregory's focus remains on social characters, where non-humans are not counted in. He has been directing Stoddart to reveal the earliest possible moments of when geography could be said to be modern. Gregory continues with his invocation of Cook's $18^{\text {th }}$ century voyages:

Stoddart argues that the work of these teams of scientists, collectors, and illustrators displayed three features of decisive significance for the formation of geography as a distinctly modern, avowedly 'objective' science: a concern for realism in description, for systematic classification in collection, and for the comparative method in explanation... it was 'the extension of [these] scientific methods of observation, classification, and comparison to peoples and societies that made our own subject possible. (Gregory, 1994: 19)

He goes on to suggest that it was through this process that 'things' were wrested from their place and set within a specific field of knowledge that has set before itself how 'things' are to be ordered. The echoes of the world as technopresence, and much of the theory developed in Chapter 2, are simply too obvious to ignore. Through Gregory's 
direction, the world as technopresence is being built within a very similar understanding to that of Heidegger, although with a specific focus on early geographers instead of simply philosophers.

In continuing with this theme, Gregory calls on Mary Louise Pratt to speak:

One by one the planet's life forms were to be drawn out of the tangled threads of their life surroundings and rewoven into European-based patterns of global unity and order. The (lettered, male, European) eye that held the system could familiarize ('naturalize') new sites/sights immediately upon contact, by incorporating them into the language of the system. The differences of distance factored themselves out of the picture... (Mary Louise Pratt, cited in Gregory, 1994: 26)

The invocation of a 'picture' here, immediately speaks to Heidegger's 'world picture'.

Indeed, as Gregory continues, the connections here are certainly intentional:

Placing other peoples and societies within its highly particular horizon of meaning had the most radical of consequences for the constitution of the human sciences and their conception of human subjects. The two 'great devices' that Stoddart singles out for particular attention in bringing 'the huge diversity of nature' within 'the bounds of reason and comprehension' - namely, classification and comparison - were the central pinions of the classical episteme. Its claims to 'truth' were not transhistorical, however, and neither was the tribunal to which it appealed. What displaced the classical episteme and inaugurated the modern episteme was, precisely, the incorporation of 'man' within the conceptual grid of European knowledge. (Gregory, 1994: 26)

Within these past two passages, the connection to the building of the systematic technological unfolding of the modern age becomes quite evident. As was discussed in Chapter 2, it is precisely the incorporation of 'man' into the 'conceptual grid', or rather into he who is responsible for the ordered unfolding of the technological mode of revealing, that first gives rise to the modern age. These conceptions echo Heidegger almost exactly: 
'We get the picture' concerning something does not mean only that what is, is set before us, is represented to us, in general, but that what is stands before us - in all that belongs to it and all that stands together in it - as a system. 'To get the picture' throbs with being acquainted with something, with being equipped and prepared for it. Where the world becomes picture, what is, in its entirety, is juxtaposed as that for which man is prepared and which, correspondingly, he therefore intends to bring before himself and have before himself, and consequently intends in a decisive sense to set in place before himself. (Heidegger, 1977: 129)

To this point, although Gregory has yet to cue Heidegger's entrance onto the stage, he has built the set appropriately for his arrival. In doing so, he has set up precisely the relationship of 'a modern mode of representation', that places the ordering of the world within a scientific framework (thought technological enframing for the purpose of this thesis) that simultaneously sees, "that [modern] 'man' was constituted as both an object of knowledge and a subject that knows," (Gregory, 1994: 26).

What is being described here is nothing less than the beginning of the domination of a technological understanding of 'things' in the world, and inevitably the decisive unfolding of 'the world' as a singular representable 'object'. This correlates perfectly with Heidegger's account of modernity generally, and technology as a way of revealing more specifically. Before Heidegger appears on Gregory's stage, there are several inferences that link this discussion to the spread of the world as technopresence. The first involves the positioning of knowledge that was to set up the temporal net described above. As Gregory says, or rather has someone else say, "beyond Europe was henceforth before Europe," (Gregory, 1994: 27). This reflects the temporal understanding of the modern conception of the world, whereby measuring the technological organisation of a society slots whatever particular nation/state/society in relation to what is on the leading 
edge (always thought of as the west or modern). The second refers directly to the circumscribing of how things are to be known, in that, "the ideas of discourse and discipline are assertively European and... they were used to administer, study, and reconstruct, and then to occupy, rule, and exploit almost the whole of the non-European world," (Gregory, 1994: 29).

At last Heidegger enters to make his grand soliloquy, spoken of course through a secondary source. At this point, Gregory politely excuses himself from following Heidegger's "abstract history" (I have yet to see a history that is not in some profound way abstract, as history is almost always a project of some present purpose projected back through time), yet allows for his character, Mitchell, to demonstrate that, "Heidegger's argument can be made to intersect in complex and historically more specific ways with the genealogy of linear perspective," (Gregory, 1994: 34). As such, Gregory asserts, under the sub-heading of Enframing the World, that the world as picture, "implies both a setting of the world in place before oneself, as an object over and against the viewing subject, and a making of the world intelligible as a systematic order through a process of enframing," (Gregory, 1994: 34, italics original). It is precisely at this point that the connections to the world as technopresence are the most apparent. Gregory goes on to invoke the linked idea of the 'camera obscura' to illustrate further what is meant by 'grasping and conceiving' the 'world as picture'. The significance of the visual metaphors of 'camera' and 'picture', are certainly intentional here, as through the development of the 'modern age', the importance attached to sight gained such ascendancy that it has virtually banished all the other senses to secondary positions. Thus, it is that the phrases 'seeing is believing' and 'I see what you mean' can only make sense 
within the modern world. As much of the discipline of geography has traditionally been built on visual representations of reality, along with the recent increase of GIS programmes within geography departments, these ideas, with their inherent 'occularcentrism', are particularly salient for geographers.

Gregory continues here by pointing to the odd modern phenomenon, whereby the subject is necessarily removed from the framework and simultaneously held within it. "Within this modern optic, the 'certainty of truth' is made to turn on the need to establish a distance between observer and observed... [so that] order may be dis-covered and represented," (Gregory, 1994: 36-7). Furthermore, for Mitchell, Gregory's stand-in for Heidegger:

Without a separation of the self from a picture... it becomes impossible to grasp 'the whole'. The experience of the world as a picture set up before a subject is linked to the unusual conception of the world as an enframed totality, something that forms a structure or system. (Mitchell, cited in Gregory, 1994: 37)

Again, the connections to the rise of geography as a modern discipline are echoed throughout this passage. These connections are not lost on Gregory and in fact he goes on to point out that:

This is a highly particular way of thinking about - and, indeed, being in the world... which is peculiar to European modernity. Indeed, nonOccidental visitors to the world exhibitions at the close of the nineteenth century saw them as emblematic of 'the strange character of the West, a place where one was continually pressed into service as a spectator by a world ordered so as to represent.' (Gregory, 1994: 37) 
This is precisely where Gregory takes the conception of the 'world as picture' and extends it into a conception of the 'world-as-exhibition', which as far as I can discern, basically amounts to the same thing.

Thus, although Gregory often distances himself from what is being proclaimed through his characters, it becomes quite clear that he is in fact concerned about the rise of the modern world. He consequently constructs the world as technopresence in much the same way that I have sought to do through this thesis, yet he seems reluctant to give to technology that position of holding a specific mode of revealing that produces the world in a peculiarly modern way. Again technology is also not showing up as a 'thing' in the world, something along side humans and nature that form the world through practical engagement. Although, he does continue to invoke the word, and I would assume the concept of, enframing, throughout the remainder of his text, he some how seems to take it as something that is indicative of a totalising meta-narrative and consequently is reluctant, in his postmodern sensitivity to address it further. However, even though he delicately tries to sidestep revealing where his sympathies lie, it is quite clear from this chapter that his conception of at least the notion of modernity falls within the scope of questioning that propelled Heidegger to write about technology. As such, there are certain segments of Geographical Imaginations that speak directly to the spread of the world as technopresence. These are most clearly defined within the first chapter, but do manage to appear sporadically throughout the remainder of the text. Throughout this opening, where before Heidegger is even mentioned, Gregory painstakingly sets the stage for the spread of the conceptual technological grid that was to become the basis for the modern age, and 
was to give rise to that singular representable whole that was to become the enframed totality as a system, or rather the modern world.

\subsection{Gregory's Postmodern Writing of a Postmodern Geography}

It would appear then, from the above argument, that Gregory has already in some way argued for the appearance of the world as technopresence. And indeed, admittedly he does go a long way into this direction of thought. However, following from what can only be described as potentially the most in depth geographical examination - of the three selected geographers - of Heidegger's later philosophy (which amounted to approximately four paragraphs) and its inherent relevance within geography, Geographical Imaginations takes a decidedly unfortunate turn into the realm of what has been poorly labelled as 'postmodernism'.

Many of the writers Gregory invokes, including Deleuze, Derrida, Foucault, Heidegger, and the like, have inspired many of the so-called postmodern literatures that pepper Geographical Imaginations. However, I have become increasingly convinced that postmodernism is at best a misnomer, and at worst a delusion that veils the ongoing evolution of modern modes of representation. In fact, none of the heroes of the postmodernist movement would dare to consider themselves as such, Heidegger included. Because they strive to overcome certain theoretical frameworks that are often associated with modernity, where metaphysics gives way to a post-metaphysics, structuralism gives way to a post-structuralism, colonialism gives way to a post-colonialism and so on, it seems that it has been assumed that, at least discursively, modernism necessarily gives 
way to a post-modernism. However, this does not necessarily follow logically. By identifying, or revealing, the often hidden processes that were inherent in the former, these inquiries do not magically erase the relationships that were derived from them. For example, to believe that writing back in the forgotten, or rather the deliberately ignored voices that were silenced (in Western academic discourse, mind you) by the process of colonisation, does not mean that the effects of such a process, or the dominant writings of a couple of centuries of Western thought, have not left an indelible mark on current relationships, as this would seem absurd. There seems to be a rather disconcerting sense here that by 'discovering' that structuralism does not actually explain everything and that there were always 'others' with distinctively separate views lurking in the shadows of colonialism, that some how we have transcended an era, and what's more that we can recognise that transcendence as such.

Furthermore, does not the labelling of an age seem to be an entirely modern phenomenon? As far as I am aware, no other 'age' recognised itself as such, or for that matter tried to overcome the tensions within their society by moving beyond it. It is, in fact, only through the modern mode of disclosure that history has become an object for 'empirical' study. Likewise, it is also only through modernism that human activity is consummated and objectified as 'culture' (Heidegger, 1977). This last point would appear to be written into Gregory's account of early explorers' contacts with 'others', along with the incorporation of peoples into the systematising grid, yet he seems to drop this point, or at least pays little attention to it through the remainder of the text.

In spite of the exceptionally strong beginning to Geographical Imaginations, the text often loses its effectiveness as it progresses. Gregory seems to get lost within his own 
creative 'playwriting', which is the result of what I take to be one of the central objectives for writing the book. That is the intentional writing of a 'postmodern' text which, in Gregory's situation, amounts to the employment of a sort of eclectic mixture of theories. The point of this style of writing is to continually give a voice to the competing voices/discourses that are often silenced within a more conventional methodology which often employs simply a singular theory that will be appealed to so that it may deliver the necessary explanation where and when it is called upon to do so. As such, Gregory's manuscript should not be readily dismissed. However, that being said, this style proves difficult for readers who are looking for a particular stance on important issues, and consequently might have difficulty extracting exactly what it is that is informing Gregory's overall academic agenda or agendas. As I hoped to demonstrate with the preceding analysis of Gregory's account of the rise of the modern world, was that the problematic of an explicitly postmodern text can be overcome by questioning the author as a director, for as eclectic as the mix of theories might be, they are still being invoked for some kind of purpose or goal. Consequently, they can still reveal certain crucial elements about the author's intentions simply by their position in the text, their tone, and the consideration given to them. Although, this was possible for an analysis of at least the first chapter of Geographical Imaginations, to extend such a technique to the whole text would prove to be an ambitious undertaking to say the least. However, by applying it to the first section, this method of questioning Gregory as a director did prove useful, I think, in determining the connections between his accounting of the rise of the world and the theory of the world as technopresence, as was developed earlier. 
Gregory's exposing of the multiple voices and geographic imaginations, as they have been presented through various texts, produces a situation where closure on any issue is intentionally removed. This is certainly useful undertaking as it leaves the possibilities of any future geographical imaginations open to be contested and made into a new image. In constructing the book as he did, Gregory recognises that the world is made into a particular configuration by the image that is producing it. Although he picks up on similar ideas about modernity that informed Heidegger's interpretation of technology, the world as technopresence can offer a significant addition to the geographical imagination. What was absent from Gregory's account, was an engagement with technology, as an actor shaping the unfolding of the world in a particular way. Thus, the world as technopresence could effectively extend the geographical imagination(s) to include non-humans within its scope of concern. By bringing technology into 'the picture' of the world Gregory constructs, his account of geography would certainly benefit, as an extremely significant force within the modern world would no longer be just a prop on the stage, rather it too would do things and take its appropriate place within the world. 


\section{Chapter Six \\ Doreen Massey's Geography: \\ Globalisation, Place, and Technology}

All distances in time and space are shrinking... Yet the frantic abolition of all distances brings no nearness... Short distance is not in itself nearness. Nor is great distance remoteness.

- Heidegger

\subsection{Introduction}

Although, initially it would seem that Massey pays particular attention to technology, as it is invoked in the titles of several of her writings, overall it appears that she treats it in much the same manner as David Harvey, albeit with a recurring focus on 
its particular implications for women. As such, having examined many of the related notions of the production of space, space-time reconfiguration, and more generally Marxian analysis, I will instead concentrate, in this Chapter, on Massey's conceptions of 'globalisation' and the inherent implications for a defining/re-defining of 'place'. In doing so, I will consider the underlying allusions to the world as technopresence, within her work (as was done with Harvey and Gregory), and will carefully sketch out the connections and discontinuities between the two.

However, my casual positioning of Massey as essentially Marxist is far too simple an accounting of her overall project. In fact, the depth of her work, her sensitivity towards women, and her openness to new ideas (arising out of what she calls a theoretical engagement with 'real issues'), often takes her well beyond the narrow scope of concern associated with a more conventional approach to historical materialism (Massey, 1999a). As such, much of her writing centres on identity, place, gender, and even Actor Network Theory (Massey, 1999a; Massey, 1999b; Massey, 1994). Following from this, it becomes clear that in spite of Massey's ongoing interest in patterns of uneven development and globalisation, she often invokes Marx, not to set a structuralist foundation to explain certain phenomena, but rather inquires openly into what it is he has to say about political economy in general and how that can be meaningfully applied to specific economic situations (Massey, 1995a).

Thus, as stated above, my primary focus for what follows will be an engagement with Massey's theorising of globalisation. This concept is both theoretically and materially linked to many of the strands of inquiry which lie within her concerns (that is as a 'real issue' facing contemporary geographers), as well it necessarily lends itself to 
the idea of the world as technopresence. Therefore, I believe that this is an appropriate issue with which to inquire into Massey's geography, as it lies at the inevitable intersection of theory and practice.

\subsection{Massey's 'Power-Geometries' and the Reining in of Globalisation}

In addressing globalisation, Massey begins with an intriguing premise, that there are, "many ways of imagining globalisation," (Massey, 1999a). Indeed there are, but as will be shown, some of her imaginings, as creative as they may be, seem to miss the underlying feature that makes the world whole, not universal or homogeneous, but rather representable as an 'object'. It is within the world as technopresence, that Massey is able to find the oppositional and forgotten voices that have been typically written out of the conventional totalising discourse of modernity. However, just because there is a flip side to every story, this does not imply that the implications of the power relationships, that are currently dominating the world, will be somehow erased when the 'other' side shows itself. Yet, neither am I implying here that the current path is some unalterable fate, and

perhaps, the presencing of the 'other' stories might spur some significant change. But first, one must begin to ask within which 'world' are these stories appearing? It is precisely this question that will need to be kept in mind while examining Massey's exploration.

Massey takes, quite correctly, the dominant form of globalisation to be the neoliberal economic expansion, emanating out of the West into 'the rest', as that which is currently unfolding. However, she cautions, "what has been forgotten in this iconic 
economics with its implicit inevitabilities is that economic globalisation can take a variety of different forms," (Massey, 1999a: 16). Massey continues with her expression of discomfort with the currently predominant globalising process:

For the imagination of this globalisation in terms of unbounded free space chimes all to well with that powerful rhetoric of neo-liberalism around 'free trade'. It is a pivotal element in a powerful, political, fully-fledged discourse. It is a discourse which is predominantly produced in the countries of the world's North. It is a discourse which has its institutions and its professionals - the IMF, the World Bank, the World Trade Organisation, Western governments. It is a discourse which is normative; and it is a discourse which has its effects.

In the world's 'South' it is this understanding of the world of the future (as unbounded global trading space) which enables the imposition of programmes of structural adjustment, with all their horrendous and welldocumented effects of polarisation, of yet-increasing hardship for the already-poor and especially for women. It is this understanding of the inevitability (unavoidability) of this form of globalisation which legitimises the enforcement of export orientation on the economy of country after country, the prioritisation of exports over production for local consumption. It is this discourse of, this particular form of, globalisation in other words which is an important component in the continuing legitimisation of the view that there is one particular model of 'development', one path to one form of 'modernisation'. (Massey, 1999a: 16)

These are precisely the concerns that have led to the current search for alternative 'paths' and for 'alternative' futures. In this rather poignant passage, Massey expresses the same unease with the notion of the 'inevitability' of the current course, as well as with the current notions of 'development' and 'modernisation', that form the basis for this thesis. What's more, she quite forcefully points out that this is but one path, and that it is not necessary for the world to unfold in this manner. The echoes of her concerns with uneven patterns of development are certainly apparent here (Massey, 1995a). To understand how the world might unfold in another manner, we must first go back to comprehend how the 
world has become the way it has. It is through this examination that one might begin to see traces of the world as technopresence within Massey's construction of modernity.

As mentioned at the outset of this thesis (Section 1.2), Massey offers an intriguing account of how globalisation is primarily conceived of in temporal terminology, with of course significant spatial implications. "Globalisation," she argues, "would seem to be an intrinsically spatial subject," (Massey, 1999a: 9). However, Massey continues, it is consistently conceived of 'a-spatially' and that this has inevitably had a profound effect on how it is unfolding, as described in the passage above. As a geographer, Massey is concerned with the notion of 'globalisation as the spatialisation of the story of modernity' which she intends to set alongside the primary conception of an a-spatial globalisation (Massey, 1999a: 10). Although, this sounds promisingly similar to the image invoked by the spread of the world as technopresence (and admittedly Massey does posit some key ideas surrounding such a process), there appear to be some difficulties with her argument for the unfolding of the 'story of modernity'.

Massey begins her recounting by taking the post-colonial interpretation of globalisation as her point of departure. The story of modernity, therefore, runs from colonisation to globalisation, where the point of such a position, "is to re-work modernity away from being the unfolding, internal story of Europe alone," (Massey, 1999a: 10). This interpretation already begins to attempt to shift the focus away from how modernity was experienced by Europe, to how it was experienced by the 'others' in the world. Massey continues, "colonisation becomes more that a kind of secondary by-product of events in Europe... rather 'it assumes the place and significance of a major, extended and ruptural world-historical event'," (Massey, 1999a: 10). It would appear that she is trying 
to demonstrate that the globalising process of European modernity was experienced in different ways beyond Europe's borders. However, although this process was necessarily experienced in 'other' profound ways outside of Europe, it was predominantly the relatively new conception of the world as a present whole that allowed for this process to be counted as a world-historical event in the first place.

Massey does seem to recognise this to a degree, as she reflects upon how the particular European discourse of early modernity legitimised the globalising practice of 'colonisation'.

It is through that Euro-centric discourse of the history of modernity that the (in fact particular and highly political) project of the generalisation across the globe of the nation-state form could be legitimated as progress, as 'natural'. Moreover, that project - of the division of the earth into bounded political entities - was just one aspect, though a particularly powerful one, of the development of a way of imagining 'cultures' and 'societies' more generally and in particular of conceptualising them as having a specific relation to space. Both cultures and societies were imagined as having an integral relation to relatively bounded spaces. (Massey, 1999a: 11)

Massey picks up on the specifically political manifestation of the rising modern technological ordering that was addressed by Harvey through the logic of capital and by Gregory through the spread of the conceptual grid associated with the rise of modern science. Thus, this 'division of the earth into bounded political entities', certainly reflects one more component of the creation of the world as being technologically present. Once again, space and the 'objects/things' that it contains (and in fact define it) must be understood in a particular way prior to the often violent practice of implementing the political control over places. Massey attributes this to the 'old' understanding of modernity as the internal story told from Europe, projected onto the rest of the planet. 
She continues by pointing out that this, "understanding of modernity enabled the establishment and universalisation of particular theoretical/conceptual frames, which in turn underpinned the material enforcement of certain ways of organising, both society and space," (Massey, 1999a: 12).

In the above argument, Massey is making the claim that thinking the globalising process of modernity from a distinctly post-colonial perspective somehow displaces the Eurocentric view of the project and consequently makes the event a significant part of the history of the distinctly non-European world. Although, there are certainly inherent dangers in recounting the story of modernity from an ethnocentric viewpoint, in that it continues to perpetuate and reproduce the power relationships that were so clearly enunciated above, it is not hard to see that this was indeed a Western project and the invocation of the 'forgotten' voices only serves to continue to grant authority to that 'old' version of the story. I presume Massey's intentions are to disrupt what she views as the linear character of globalisation's current configuration.

It is at this point that Massey introduces her notion of the ascendancy of the temporal over the spatial within the conceptualisation of globalisation. It is precisely these arguments that introduce so well the temporal dimension of the world as technopresence. Massey asserts:

Most evidently, the standard version of the story of modernity - as a narrative of progress emanating from Europe - represents a discursive victory of time over space. That is to say that differences which are truly spatial are interpreted as being differences in temporal development differences in the stage of progress reached. Spatial differences are reconvened as temporal sequence. Thus, Western Europe is understood as being 'advanced', other parts of the world as 'some way behind' and yet others as 'backward'. Euphemistically to re-label 'backward' as 
'developing' does nothing to alter this process of thinking of spatial variations in terms of a temporal series. (Massey, 1999a: 13)

This elucidation of the temporal component of the modern world, describes the processes involved in the legitimisation of many of the current political and material practices. As such, Massey's conceptualisation here of the temporal net blanketing the globe in popular Western discourse manages to move well beyond Harvey's conception of the transformation of capitalist practices, and to some degree echoes those sentiments expressed by Gregory's invocation of 'what was beyond Europe was necessarily before Europe'. In her efforts to elaborate on the often missing temporal dimension of globalisation and to spatialise precisely that discourse, she apparently misses the spatial strategies that were inherent within the early spread of modernism across the globe. This is, however, well developed within Gregory's text as was demonstrated above (see Chapter 5).

For Massey, though, the effect of spatialising the predominantly temporal understanding of the story of modernity is the opening of spaces that will allow for differences to have a place, these spaces are to be understood, I presume, as entirely separate from the spatial strategies of familiarising a landscape within a taxonomic ordering of reality. Thus, by allowing 'true' spaces, of difference, a place within the process of globalisation, it is assumed that alternative temporal trajectories will be allowed to surface, in turn gaining a voice within the process, and inevitably altering social relations and organisation in distinctly new ways (Massey, 1999a). Therefore, Massey sees the production of a genuinely spatialised process of globalisation as a real 
possibility for disrupting the current unfolding of neo-liberal globalisation along with the conceptual invocations of 'progress' and 'development'.

\subsection{Space-time and Technopresence}

Massey's interpretation of globalisation presents some intriguing common ground with the idea of the world as technopresence. By pointing to the privileging of the temporal over the spatial she adds a key component in the appearance of a technopresent world (as was described above). Having examined some of the implications of a systematic spatial gathering into an ordered whole within Harvey and Gregory, Massey's globalising temporal net provides an interesting angle for imagining the world as technopresence. However, by challenging the position of time over space, Massey's suggestions for re-thinking the course of globalisation presents several ideas that hold some significance for this discussion.

For Massey, "space must be conceptualised integrally with time, in terms of space-time," (Peet, 1998: 288). This space-time, in turn, should be conceptualised, "as relative (defined in terms of the entities 'within' it), relational (as constituted through the operation of social relations, through which the 'entities' are also constituted) and integral to the constitution of the entities themselves (the entities are local time-spaces)," (Massey, 1999b: 262). The similarities, in the description, to my employment of Heidegger and Latour to build the world as technopresence are remarkable. In particular, the above line of reasoning speaks almost directly to the idea of how things are disclosed. First, by stating that space-time be conceptualised 'as constituted in terms of the entities within it', this directly reflects Heidegger's being-in-the-world. In this sense, space and 
time are defined by what is present. Second, the statement that space-time is relational, in that it is 'constituted through the operation of social relations, through which the entities are also constituted', begins to draw in Latour, as well as Heidegger. It is not only what is present, but our practical engagement with things that construct the world around us. And third, the statement that 'the entities are (manifested) local timespaces', speaks to the appearance of the world within a particular historical and geographical context.

What is missing from the above description is the role of technology in disclosing entities as objects ready-at-hand, in playing a significant part in human/non-human interaction, and in forming a world that holds everything together in an ordered whole. From Massey's interpretation of globalisation as the erasure of spatial difference within a sequence of temporal stages to her call for the re-unification of space and time to form space-time, what seems to be absent is a consideration of technology. By seeking to respatialise, what she sees as a predominantly temporal understanding of the world, Massey intends to open spaces that will allow for a chorus of different time-space trajectories to burst into the world, fracturing it into a plurality of local worlds, linked in myriad ways (Massey, 1999a; Massey, 1999b). this is not intended to imply that each 'space' will have a fixed 'identity', rather 'spaces', 'places', and 'identities' are not static but are continually re-forming with each relational change (Peet, 1998).

However, I suggest that if we do not consider the current engagement with technology, while we are re-considering space and time, then the 'entities' and our relationship with them will not necessarily change. What thinking the world as technopresence can offer here is some insight into what it is that is producing the single 
world. By thinking of 'things' as technopresent in the world, the relational construction of space and time, of space-time, appears in the particular manner that seems to produce the singular path of globalisation that Massey seeks to disrupt. As has been suggested in this thesis, technology first discloses 'entities' as raw material to be taken up into the technological framework. Second, practical engagement with technology in everyday activities serves to perpetuate the technological disclosure of things and compels society into a specific set of social organisation and relationships. And, third, by thinking the world as technopresence, which is the manifestation of the first two points, one's attention shifts to how it is that those entities show up to define the conceptions of space and time. Thus, by adopting the concept of the world as technopresence, one can begin to see where attention might be given so as to alter the current configuration of globalisation's unfolding. In order to accomplish the 're-spatialising' that Massey is seeking, it would prove useful to consider seriously the role of technology in the production of 'the world' that is currently dominating this process. 


\section{Chapter Seven \\ Re-Thinking the World \\ From Technopresence to Ecopresence}

Your true modern is separated from the land by many middlemen, and by innumerable physical gadgets. He had no vital relation to it; to him it is the space between cities on which crops grow. Turn him loose for a day on the land, and if the spot does not happen to be a golf links or a 'scenic' area, he is bored stiff. If crops could be raised by hydroponics instead of farming, it would suit him very well. Synthetic substitutes for wood, leather, wool, and other natural land products suit him better than the originals. In short, land is something he has 'outgrown'. - Aldo Leopold (1949)

\subsection{The Geographical Imperative}

What has been arrived at, thus far, through this philosophical inquiry? As geographers we have been questioning the world, that built graticule that stretches over the Earth. Technology, then, is that convention that has been given the position of apprehending (thought currently as producing) that which appears in the world. As such, 
what has been shown is that through the dominant forces shaping human society and now even the physical environment, the world is currently thought in terms of technopresence. When questioning technology then, the question becomes one of a world producing/disclosing force that must become part of the geographic vocabulary if geographers are to ever begin to understand how the world is unfolding. Else, what is witnessed is the continual spinning of wheels within an already presupposed world that forms the ontological starting point for most geographic studies. Even those geographers who choose to challenge the universal promises of the modern world, often end up in a position where they simply uncover certain gaps and discrepancies (usually through the re-reading of specific philosophical texts) between the representations of reality and what they feel are the underlying contestation and continual 'becoming' of 'real' worlds. This usually leads to some sort of self-congratulatory state of achievement, which is presented through geographic literature as the geography of 'postmodern' world(s). I, however, am not convinced that by identifying the differences written out by the totalising narrative of modernity, through new discourses or the increasingly popular deconstructionism of 'poststructuralist' methodology, that we have somehow magically escaped the grasp of the technical reality that underlies the basis of the 'modern age'. However, if there really is a growing disenchantment with the current configuration of the world, what needs to be thought about is precisely that which produces such an entity in the first place. It seems to be intuitively obvious that if one wishes to make a significant change to how things are, then what warrants the most pressing attention is that which defines them as such. 
We (geographers) appear to be less concerned about the world, and more concerned about what is in the world. Consequently, we tinker with components of nature and society, postulate theories to explain certain phenomena, and describe processes that are occurring, be they social or physical. All the while, the world itself seems to be a taken-for-granted backdrop, something that is already there, or more intriguing something that has always been there. As such, we rail against certain technologies, specific social practices, and wonder why 'nature' can not be written significantly back into our politics, without necessarily questioning what 'kind' of entity it is that contains these technologies, sets of social practices, and yes, even nature itself.

The intent of this thesis, as stated above (Chapter 2), has not been to set the world as technopresence as a deterministic entity that dictates the exact course of all action, practice, and things, everywhere on Earth. Instead, it has sought to think through one way of how the world appears and link it with a metaphysics that could produce such a 'thing' as 'the world' in the first place. Consequently it has attempted to open a way of thinking about the rise of the 'modern world'. Is this not the task of human geography, to explore (graph) the world that humans occupy? What has been suggested in this study is that what is considered under the auspicious conception of the modern world is shown to be, in a significant way, derived from the history of a distinctly western metaphysics. As such, arguing that the modern world appears as one of technopresence is not an argument that seeks to explain all phenomena in the world through a singular meta-narrative. Rather, it presents a theory that might be useful in extending geographic inquiry beyond its current engagement with 'things' in the world, to the production of the world as a 'thing' itself. 
If, as has been shown, technology has settled into that position which produces a certain understanding of the world, and that the modern age with the associated ascendancy of science and machine technology has arisen out of such an understanding, then it seems imperative to challenge the legitimacy of its basis. Furthermore, as more of the world's population is mobilised into this relationship with the Earth, through the globalising reach of such an understanding, the urgency for questioning the foundation of the world that is being produced indeed becomes a geographic imperative. This might be misinterpreted as being a foundationalist approach, one that seeks to identify a single foundation around which everything revolves and out of which everything evolves. However, this is not exactly the case. What has been sought here has been a locating of the dominant paths that have led to the dominant understanding that can currently be seen as forming the basis for many aspects of contemporary social life. This is seen, not only in the west, but has spread out from the west, first through colonialism and more recently through the economic colonialism of neo-liberal globalisation. It can probably be safely assumed that everyone everywhere is at least in someway impacted by the systematic technological grid. Whether it is through the division of space into nation-state containers (which are represented by a political map of the world), or through the more subtle implications of global climate change, or through the recent search for isolated gene stocks to further the Human Genome Project and its affiliated genetic research branches, the modern world has certainly made itself present with an unprecedented range and scale.

As was shown within the examination of Harvey, Gregory, and Massey, thinking the world as technopresence can offer possibilities for re-considering the role of 
technology. With Harvey, as with Marx, the world as technopresence offers a flip on the modes of production - modes of representation relationship. It suggests that it is not only through a practical engagement with technology that the world is made into a particular unfolding, rather what operates within an equally significant sphere is the disclosure/understanding of things as raw material. This stems from a long history of western philosophy, as opposed to an explicit history of 'capitalism' alone. As will be suggested in the next section, considering technology in this manner shifts the focus of where one's attention should be given to overcome the current state of the world. Of course, the political angles to Harvey's work are important, but the world as technopresence suggests that it might be through a closer inspection of technology, how we view the world that could lead to potentially more appropriate starting points for shifting the current social and environmental relationships in new directions.

For Gregory, the world as technopresence speaks to certain imaginations within his Geographical Imaginations. Although Gregory's work opens up the possibility for differences, by giving voices to those forgotten 'others', I feel that unless this coupled with a thorough consideration of technology, many of those voices will still just arise within the framework of a larger technological system. As the world has become effectively a whole, and many of its institutions have been derived from a technological disclosure of things, I fear that unless this situation is re-considered with an emphasis on technology, those other voices will only show up in relation to the current ordering of the world.

What seemed to be missing in Massey's account of globalisation and space-time, more generally, was any real consideration of the role of technology. For me, Massey 
goes a long way into describing the relative and relational processes underlying the production of the world (i.e. certain conceptualisations of space and time). However, by ignoring technology's explicit role within these processes, it seems that Massey's respatialising of globalisation will fail to come to terms with many of 'entities' that are defining her space-time trajectories and configurations. By thinking of technology in the manner suggested by this thesis, the possibility for moving beyond the current state of things becomes possible only if our relationship to technology is considered in full.

\subsection{Thinking the World as Ecopresence}

Having questioned technology as a world-disclosing horizon, which is the dominant mode of revealing within the modern age, I suggest that there are perhaps more appropriate concepts within our grasp that can fill that position. However, as should be obvious from the argument presented in this thesis, the basic ideas that produce an age do not fall into place overnight, nor are they wholly within the reach of any individual. Descartes, in spite of his self-imposed isolation in Amsterdam and his meditative journey into his own mind, existed at a time and in a place that was slowly transforming. There were myriad ways in which certain thoughts and endeavours, each with their own players and histories (perhaps his insistence on proving the existence of God was in part derived from the known accounts of Galileo's story), were interacting in a manner that was shaped by context and consequently produced new ones. I will not pretend to be able to reproduce the specifics of such a situation, or to understand how that world was. However, as this study has been one that is inquiring philosophically, I will constrain 
myself to the flow of ideas, the further clarification of contemporary understanding, and the observable manifestations of said ideas.

In today's society, at least here in North America, there has been the increasing expectation of instant gratification. This expectation, that everything must be solved immediately, is not surprising given the superficial pace of life that is experienced through most everyday activities. However, as has been shown above, the roots of contemporary ills within the world have a long history in the gradual transformation of concepts which take hold as modes of revealing. Therefore, what must first be taken into account when considering shifts in concepts that exist in the realm of world-disclosing horizons, is patience. This patience should not be read as a prescription for inaction, rather it arises from the idea of vision beyond one's own finite existence. Historically, many of the human accomplishments that are thought of as holding 'greatness', were begun on their way by an individual that sought to bring them into appearance and typically did not live (nor did they expect to, for that matter) to see their inevitable completion (e.g. the Taj Mahal, the Great Pyramids, St. Peter's Basilica, Temple de Sagrada Familia, etc.). Today, not only do we see a lack of vision beyond our own finitude, but we also witness the continual difficulty of engaging with issues that extend beyond our myopic obsession with the present (e.g. the failure to ratify the Kyoto Protocol in any significant way; the continual re-writing of Canada's Species at Risk Act). Perhaps, what is needed is to take seriously those ideas that have been forwarded by distinctly non-western philosophies, such as the North American Aboriginal conception of planning for 'seven generations in advance'. This means that any action taken will consider the implications for at least seven generations into the future, which implies a 
vision beyond the temporal trap of, "neo-classical economics which apparently has difficulty seeing beyond tomorrow," (Ralph Perrault, Elder of the Garden River First Nation, 2002).

'Expectation', therefore, consistently ties us into the present moment, erasing a connection to the past and removing the possibility of alternative futures. 'Vision', however, is that which can carry us beyond the present. The play between these two concepts becomes one of utmost significance whenever one is discussing potential changes to the world, considering both the environment and politics. If we begin to think in terms of vision, then, real progress is not entirely measured through speed of implementation. Now, this is a difficult position to put forward, but it is certainly one which I feel has been neglected for far too long. Cronon (1995), quite perceptively states that, "at a time when threats to the environment have never been greater, it may be tempting to believe that people need to be mounting the barricades rather than asking abstract questions." Considering then, this, seemingly urgent need for immediate action that is resulting from a sustained assault on the environment, it would appear as though speaking of vision beyond our lifetime sidesteps the issues and holds out for some passive hope that things will change. This is certainly not the case. In fact, vision implies action on all levels (material and discursive) as it does not seek to arrest any attempts to make things 'better', rather it challenges the expectations that we have come to accept, and offers in its stead the possibility of building the world in a new image. The concept of 'vision' here, and the Aboriginal philosophy from which it is derived, should not be read as synonymous with the vague notion of 'sustainable development' that has been floating around contemporary environmental discourse for at least the last 15 years or so. 
Sustainable development appears to take the present course of development and project it into the future, in an attempt to find a way whereby, through certain modifications to the current system, the course of present society will be able to reproduce itself ad infinitum. Of course, there are countless definitions of 'sustainable development', where the most well known is obviously the one espoused in Our Common Future, but this is precisely the point. Although, the concept is vague, the term itself is revealed in the use of the word 'development', where there are no indications that it has moved beyond appealing to those concepts of 'development' and 'progress' that have been the basis of the challenge forwarded in this thesis. In short, they are still well within the confines of the world as technopresence, stuck in the discourse of ecological crises and technical solutions.

It is through an acceptance of that seemingly forgotten patience (vision) that one can begin to trace the potential shifts that might replace technology as the worlddisclosing horizon, and as such, shift the world beyond what is understood as the modern age. They are there, however, they have yet to be thought of as that which begins society on a way. Rather, they have been consistently viewed as prescriptions for immediate action, or simple critiques of specific material practices. Having inquired into technology as a world-disclosing horizon, this thesis has traced (primarily through Heidegger) the path that has led to the appearance of the 'modern age'. Similarly, when searching for an alternative mode of world disclosure, one should not concentrate only on what is current, but instead trace the path of concepts that have been increasingly persistent within and antagonistic to the dominant modes of understanding. I would suggest that the notion of 
ecology has been one such concept, and perhaps is slowly rising to such a position that may offer a way out of the current domination of the world as technopresence.

In spite of the proliferation of so-called postmodern literature, art, architecture, and theory that has surfaced through the past half a century, this time is not effectively a postmodern time. What has resulted from this literature, however, has been the continual, albeit often confused, exposure of the tensions between intentional reality, formal reality, and representational reality. As well, the past century has produced a greater interest in the environment, which has consequently inspired many of the postmodern discourses, as conceptions of nature have often been forwarded as an appropriate starting point for questions about reality; the connections between modernity and the way the environment is viewed are striking here (Braun and Castree, 1998; Cronon, 1995). It is from such beginnings, that I have suggested that it is in fact the notion of ecology that will begin to form the basis for the next age; where the modern age is thought 'technological', the next age will be thought 'ecological' (I am intentionally avoiding the invocation of the term postmodern as this still measures from the present). But first ecology must be subjected to the same scrutiny that was accorded to technology.

I have intentionally been using the 'notion of ecology', thus far, so as to distinguish it from the 'science of ecology' which fits more within a modern technological understanding of nature. The notion of ecology intends to move beyond, "environmentalism [which] is used to refer to a traditional, human-centred approach that sees the natural world as that which surrounds human beings, [where] ecology is reserved for a more holistic view that rethinks the place of humanity within a larger system or whole," (Zimmerman, 1998). Of course, there are innumerable branches of both 
environmentalism and ecology, but the above description will be used loosely to examine the ideas behind ecology. Here, the notion of ecology is to be thought as that which is antithetical to modern science, in that it is inherently anti-reductionist. Whereas, the science of ecology can be thought in terms of reducing ecosystems to biology, to chemistry, to physics, and finally to mathematics, the notion of ecology seeks to move in an opposite direction which builds complexities and interconnections, and does not count humans as somehow 'unnatural' (Barbour, in Cronon, 1995). It is not about an externalised nature of objects that can be known by human subjects; rather it refers to the abolition of any distinction between humans and their environment, as they are inherently thought together. Both Braun and Castree's Remaking Reality: Nature at the Millenium (1998) and Cronon's Uncommon Ground: Rethinking the Human Place in Nature (1995) have gone a long way into rethinking the artificial divide that has separated, philosophically, humans from their environment for a considerable amount of time. As such, these books, intriguingly both edited by geographers, have begun to establish the questions that lead to an inevitable confrontation with world-disclosing horizons.

These pieces of literature, nonetheless, have not arisen ahistorically. They are in part a response to the seemingly difficult task of incorporating more environmentally sound philosophies into political realities. Furthermore, the sheer scale of impact current configurations of human interaction and social processes are having, where recently international scientists have issued in the geologic period of the 'Anthropocene', "where a dramatic new series of forces have been unloosed in the planetary biosphere changing the atmosphere as well as geomorphic processes and most natural cycles that involve a biomass of any substantial size," has led to a certain unease with conventional 
environmental literature (Dalby, 2002). Although Dalby's concern is explicitly located in rethinking the discourse of international relations, it is essentially derived from the same concerns that led others to begin to rethink the effectiveness of the terms that are used so commonly to invoke conceptions of nature. For Dalby (2002), "ecology suggests a vocabulary of connections that is not necessarily obvious in Anglo-American environmentalist thought... with their implicit and explicit assumptions of empty natures and pristine wilderness on the one hand, and the necessity of administration of these spaces in terms of resources on the other." As such, these geographers (Cronon, Braun and Castree, and Dalby) can be seen as being frustrated with the ineffectiveness of a century of environmental thought, and are consequently, whether intentionally or not, trying to trace the source of such frustrations to the discrepancies between the dominant mode of disclosing the world, through a technological framework, and a readily available alternative that has not ascended to a position that can unleash the significant change that is desired. However, as has been stated above, perhaps the assessment of such in-roads for ecological thought should not be measured entirely by their failure to realise instantaneous results, rather they should be thought of as building a way for the world as ecopresence to come into appearance.

Admittedly, this is a hard pill to swallow, as it implies that there will be many more environments destroyed, many more ecological disasters, many more deaths and illnesses related to environmental contaminants, further reduction in natural habitats (thought for human and animal alike), and the continued disappearance of varied species. Again, I would like to reiterate that this is not a prescription for continued inaction, as a number of local and regional initiatives have been somewhat successful in slowing the 
pace of destruction. Rather, it reflects on an opening for a way to profoundly alter the course of the world's unfolding, the kind of change that does not easily lend itself to 'overnight delivery'.

\subsection{Shifting from Technopresence to Ecopresence}

What has been shown through this inquiring into technology is that we are born into a world that holds particular views, definitions, and understandings. These in turn, produce specific categories, vocabularies, and philosophies. From this, we begin to compare and contrast these given vocabularies to our experiences within the world. As such, the world you or I have inherited is not the same as those of the previous generation. Following from this, the world that will be inherited by the next several generations will continue to hold the residual traces of previous generations.

The optimism that can then arise here is that although current environmentalists lament about the inability to fix spatially those defects they see with how things are, a temporal understanding will prove to be much more effective. The world that appears then begins to change accordingly. The ideology that arose out of 1960 s North America, that gave rise to the first Earth Day in 1970, was the beginning of a mass environmental consciousness within society. Although, most of this has not had the significant impacts that the 'popular' environmental movement had intended, there has since been a continued building on those ideas, just as they had built their ideas on the conservationists and naturalists that had preceded them (e.g. Leopold, Thoreau, and Muir). Unfortunately, most of those individuals who made such environmentalism 'popular' have regressed into the simple 'real world' concerns with which they had 
rallied against. Their slogans of protest have been replaced with platitudes such as 'ideals are the luxury of youth' and 'we've got to make a living somehow'. However, there is a cumulative effect that is observable, as today's children are now being taught about environmental concepts throughout their schooling (although this teaching might also require some further tweaking). What's more, they are also experiencing first hand smog advisory days, drinking water quality alerts, water shortages, a proliferation of allergies, persistent diseases in livestock, proliferation of cancers, ultraviolet radiation warnings, pharmaceutical recalls, etc. And these are occurring within the 'so-called' technologically and socially advanced nations. Will this not begin to influence how the world is viewed? Is it any wonder, then, that most environmental visions appear apocalyptic, when those of us who are apparently 'fortunate' enough to be on the leading edge of technological progress are mired in the environmental consequences of our actions that seem to be continually externalised from the dominant discourses of 'progress' and 'development'?

Following from this, it appears as though The Brundtland Commission got it wrong. What is needed is not the preserving of pieces of land in a state of perpetual stasis, nor is it the prediction of what future generations will need for resources and saving them some, nor is it choosing specific species to protect so that our descendants can also marvel at them. What is needed most is the setting in motion of an overthrow of precisely the technical system that produces such concerns in the first place. It is the toppling of the world as technopresence that is required, no it is 'essential'. Therefore, the demand put forward to us, is that we begin to produce an understanding of the world that is entirely different than that with which we struggle today. It is time for a new 
vocabulary, new categories, and new philosophies for engaging the world. These are, admittedly, already well underway, yet there remains an ongoing tension between these concepts and those with which society is hesitant to dispose of, producing the frustration that has been described above. Consequently, we might never see these concepts gain the ascendancy that we wish for them, but again it is only recently that we have come to expect such instantaneous results.

The world as technopresence has reigned for a few centuries, or developed through a couple of millennia (depending on how you read the philosophy) and consequently its overturning will not occur in the time scale we have become accustomed to. What must be done now is the sowing of the seeds of change, both discursively and materially. The world as it is will not easily lend itself to the kind of significant change that is required. All we can do is to prepare the way for its coming into appearance. It will not suit us to simply rail against technology and its ordered reality; nor would it be useful to attack science as a way of knowing. What is necessary is to challenge technology as a world-disclosing horizon with all of its implications that have been developed throughout this thesis. It is through this line of questioning that a way for a new mode of revealing can begin to take its place, one based on avowedly less narrow conceptions than that which currently grips the world. This will begin the necessary discursive shift in how the world is spoken about.

Simultaneously, in order for earthly things (including humans) to be disclosed in a way beyond technological representations, they must be at least present, or accessible. As such, the current configuration of cities (and the frightening increase in urban migration) will not suffice for any significant shift in understanding; in fact they will perpetuate the 
current understanding of a technical relationship with the land, as food appears in supermarkets, sewage and waste are removed promptly and regularly, and power and water are delivered from seemingly out of nowhere. This is the world manifested as technopresence, where everything appears to be accounted for, everything is a means to some other ends, everywhere is somewhere, and every 'thing' has its function. By contrast, even those rural communities just slightly removed from the urban grid can be seen as existing within a potentially different relationship to the land. Where water comes from a well, one is constantly aware of water quality and quantity; where sewage is 'flushed' to a septic system, one is conscious of volume and items being disposed of; and, where garbage is taken to the local dump, one is reminded weekly that it too goes 'somewhere'. This is not to say that currently, even these rural communities are completely removed from the world as technopresence, as they still exist in specific jurisdictions, they typically obtain power, food, and other consumer items through a much larger network that continues to exemplify the technological age. However, what can be seen is that the potential for a new relationship exists in certain spaces more than others. As such, geography is very much an appropriate discipline from which to think of constructing spaces for the shift from the world as technopresence to one of ecopresence.

Geographic studies into the urban landscape, urban ecology, urban planning and so on, are too numerous to summarise here. However, the prominence of urban populations and the increase in urban migration presents enormous problems for thinking the world beyond technopresence. Recent urban initiatives to develop community gardens on vacant plots of land and the greening of city rooftops appear to be moving cities in a direction that could begin to open up a limited relationship with the land. 
Unfortunately, the situation needs to move beyond these initiatives to incorporate novel concepts that might make the idea of clean rivers and clean waterfronts a potential reality. As it stands now, it seems to be accepted that urban waterways are by their very nature polluted. There is, consequently, much more research that needs to be carried out to determine appropriate configurations that could raze current urban constructions and raise a novel urban ecological structure.

By replacing technology as that which discloses the world with ecology, then the world will inevitably change as well. With a singular framework that has been appealed to for too long now, we see what is observable today; that unidirectional understanding of 'progress' and 'development'. Really, how could we see anything else? To disrupt these notions, we can think through the potential that ecology can offer as a world disclosing horizon. Ecology, as discussed above, takes into account both humans and nature, in that it asserts that the difference has been artificial. Instead, what is left is a home, a place for dwelling. In the technological age's rush to build, what has been seemingly forgotten in the architectural plans, is that people need a living space. By thinking the disclosure of the world ecologically, this 'living space' would be written back into the landscape. That is, the predominantly utilitarian landscape that exists in the modern age would give way to a living landscape, where a relationship with technological mediation would diminish and a relationship with the land could begin to redevelop. The world that would then appear would be the world as ecopresence. With the world as ecopresence, we are necessarily more connected to earthly things in a variety of ways. The objects found in the world will no longer be mere technical representations. We will get dirty, struggle with an apparent loss of order, and break with certain assumptions about what counts as 
real (i.e. what counts as urban vs. what counts as nature). This does not imply the total abandonment of technology, or the dismissal of modern science, rather it provides for an assessment of such pursuits measuring more ways than forward. It would also, hopefully, provide for the possibility of abandoning certain technological and scientific pursuits, with out the current rhetoric of 'not being able to go back'.

Ironically, the social and environmental interconnections born out of the systematic technological unfolding of the modern world, which currently serve to perpetuate those relationships, might also be those that can lead to the emergence of a shifting world-disclosing horizon. Although it might be too soon to state authoritatively that ecology will eclipse technology as that which forms the basis of a profoundly new age, perhaps, like those Europeans living in the $16^{\text {th }}$ and $17^{\text {th }}$ centuries, we are witnessing the beginnings of an epochal transformation that has yet to unfold into a world of its own.

Descartes said of his famous Meditations, "I would even add that these arguments are such that I do not think there is any way in which human intelligence could ever discover better ones," (Descartes, 1641). If, as is commonly espoused, his philosophy is taken to be the basis of the 'modern age', then it is with an ironic twist that the philosophies that are shaping up to move the world in new directions, are all attempting to reattach the mind to the body and by extension humans to nature. It is a delicate surgery, but it is one that offers the possibilities of 'the better life' that was originally promised by the initial decapitation. 


\section{References and Select Bibliography:}

Armstrong, Marc 2000. Geography and Computational Science. Annals of the Association of American Geographers, V. 90(1): 146-156.

Adams, Paul 1998. Network Topologies and Virtual Place. Annals of the Association of American Geographers, V. 88(1): 88-106.

Adams, Paul 1992. Television as Gathering Place. Annals of the Association of American Geographers, V. 82(1): 117-135.

Agnew, John 1998. Geopolitics: Re-Visioning World Politics. Routledge, London

Barnes, Trevor 2001. Lives Lived and Lives Told: Biographies of Geography's Quantitative Revolution. Environment and Planning D: Society and Space, V. 19: 409429.

Barnes, Trevor 1998. A History of Regression: Actors, Networks, Machines, and Numbers. Environment and Planning A, V. 30: 203-223.

Bathelt, Harald and Hecht, Alfred 1990. Key Technology Industries in the Waterloo Region: Canada's Technology Triangle (CTT). The Canadian Geographer, V. 34(3): 225-34.

Bertrand, Nathalie 1999. Contribution des Technologies d'Information et de Communication au Développement. The Canadian Geographer, V. 43(2): 134-44.

Bijker, Wiebe and Law, John 1992 (eds.). Shaping Technology/Building Society: Studies in Sociotechnical Change. MIT Press, Cambridge, Mass.

Braun, Bruce and Castree, Noel 1998 (eds.). Remaking Reality: Nature at the Millenium. Routledge, New York.

Braun, B. and Castree, N. 1998. "The Construction of Nature and the Nature of Construction: Analytical and Political Tools for Building Survivable Futures" in Remaking Reality (eds.) B. Braun and N. Castree. Routledge, New York.

Breheny, Michael 1995. The Compact City and Transport Energy Consumption. Transactions of the Institute of British Geographers, V. 20(1): 81-101.

Bunkśe, Edmunds 1990. Saint-Exupéry's Geography Lesson: Art and Science in the Creation and Cultivation of Landscape Values. Annals of the Association of American Geographers, V. 80 No. 1: 96-108. 
Ceccato, Vania, Haining, Robert and Signoretta, Paola 2002. Exploring Offence Statistics in Stockholm City Using Spatial Analysis Tools. Annals of the Association of American Geographers, V. 92(1): 29-51.

Conley, Verena Andermatt (ed.) 1993. Rethinking Technologies. University of Minnesota Press, Minneapolis.

Conley, Verena Andermatt 1993. "Eco-Subjects" in Rethinking Technologies (ed.) V. Conley. University of Minnesota Press, Minneapolis.

Cooley, Mike 1987. Architect or Bee? The Human Price of Technology. Cox \& Wyman Ltd., Reading.

Cosgrove, Denis 1994. Contested Global Visions: One-World, Whole-Earth, and the Apollo Space Photographs. Annals of the Association of American Geographers, 84(2): 270-294.

Côté, Serge 1999. Les NTIC et le Développement des Régions: Une Réflexion à Poursuivre. The Canadian Geographer, V. 43(2): 126-33.

Crang, Mike, Crang, Phil, and May, Jon 1999. Virtual Geographies: Bodies, Space and Relations. Routledge, London.

Crang, Mike and Thrift, Nigel (eds.) 2000. Thinking Space. Routledge, London.

Cronon, William (ed.) 1995. Uncommon Ground: Rethinking the Human Place in Nature. W.W. Norton \& Co., New York.

Curry, Michael 1997. The Digital Individual and the Private Realm. Annals of the Association of American Geographers, V. 87 No. 4: 681-699.

Dalby, Simon 2002. Environmental Security: Ecology or International Relations? From a paper presented at The Annual Convention of the International Studies Association, New Orleans, March 2002.

Demeritt, David 2001. The Construction of Global Warming and the Politics of Science. Annals of the Association of American Geographers, V. 91(2): 307-337.

Demeritt, David 1996. Social Theory and the Reconstruction of Science and Geography. Transactions of the Institute of British Geographers, V. 21(3): 484-503.

Descartes, René 1998 [1641]. Meditations and Other Metaphysical Writings. Penguin Books Canada, Toronto. 
Diamond, Derek 1995. Geography and Planning in the Information Age. Transactions of the Institute of British Geographers, V. 20(2): 131-138.

Dorn, J. and Northern Native Broadcasting, Yukon, 1997 (citation by Friends of the Wolf). The River of Life: 40 Mile Caribou. Video (57:50)

Elmes, Gregory and Harris, Trevor 1996. Industrial Restructuring and the United States Coal-Energy System, 1972-1990: Regulatory Change, Technological Fixes, and Corporate Control. Annals of the Association of American Geographers, V. 86(3): 507529.

Fabrikant, Sara and Buttenfield, Barbara 2001. Formalizing Semantic Spaces for Information Access. Annals of the Association of American Geographers, 91(2): 263280 .

Feldman, Maryann and Florida, Richard 1994. The Geographic Sources of Innovation: Technological Infrastructure and Product Innovation in the United States. Annals of the Association of American Geographers, V. 84(2): 210-229.

Field, Neil 1991. Population Analysis on the Microcomputer: A System of Software Packages. The Canadian Geographer, V. 35(1): 23-36.

Fortin, Andrée et Sanderson, Duncan 1999. Espace Social Communautaire et Virtuel: Continuités et Discontinuités. The Canadian Geographer, V. 43(2): 184-90.

Froehling, Oliver 1997. The Cyberspace "War of Ink and Internet" in Chiapas, Mexico. The Geographical Review, V. 87 No. 2: 291-307.

Gigon, Nathalie et Crevoisier, Olivier 1999. Internet et la Recomposition Territoriale des Relations dans L'Agriculture Suisse. The Canadian Geographer, V. 43(2): 152-60.

Gilbert, Anne and Villeneuve, Paul 1999. Social Space, Regional Development, and the Infobahn. The Canadian Geographer, V. 43(2): 114-17.

Goodchild, Michael 2000. Communicating Geographic Information in a Digital Age. Annals of the Association of American Geographers, V. 90 No. 2: 344-355.

Grasland, Loic 1999. Internet Est-il Soluble dans L'Espace? Réflections sur la Diffusion du Web en France. The Canadian Geographer, V. 43(2): 144-51.

Gregory, Derek 1994. Geographical Imaginations. Blackwell Publishers, Cambridge, Massachusetts.

Gregory, Derek 1995. A Geographical Unconscious: Spaces for Dialogue and Difference. Annals of the Association of American Geographers, V. 85 No. 1: 175-186. 
Habermas, Jürgen 1987. The Philosophical Discourse of Modernity: Twelve Lectures. MIT Press, Cambridge, Mass.

Hacking, Ian 1990. The Taming of Chance. Cambridge University Press, Cambridge.

Hacking, Ian 1983. Representing and Intervening. Cambridge University Press, Cambridge.

Haraway, Donna 1991. Simians, Cyborgs and Women: the reinvention of nature. Free Association Books, London.

Harrison, Stephan and Dunham, Philip 1998. Decoherence, Quantum Theory and Their Implications for the Philosophy of Geomorphology. Transactions of the Institute of British Geographers, V. 23(4): 501-514.

Harvey, David 2000. Spaces of Hope. University of California Press, Berkley and Los Angeles.

Harvey, David 1996. Justice, Nature and the Geography of Difference. Blackwell Publishers Inc., Cambridge, Mass.

Harvey, David 1995. Geographical Knowledge in the Eye of Power: Reflections on Derek Gregory's Geographical Imaginations. Annals of the Association of American Geographers, V. 85 No. 1: 160-164.

Harvey, David 1989. The Condition of Postmodernity: An Enquiry into the Origins of Cultural Change. Blackwell Publishers Inc., Cambridge, Mass.

Harvey, David 1982. The Limits to Capital. Basil Blackwell Ltd., Oxford.

Heidegger, Martin 1962. Being and Time. Basil Blackwell Ltd., Oxford.

Heidegger, Martin 1968. What is Called Thinking? Harper \& Row Publishers, New York.

Heidegger, Martin 1971. Poetry, Language, Thought. Harper \& Row Publishers, New York.

Heidegger, Martin 1977. The Question Concerning Technology and Other Essays. Harper \& Row Publishers, New York.

Heidegger, Martin 1998. Pathmarks. Cambridge University Press, Cambridge.

Hoeschele, Wolfgang 2000. Geographic Information Engineering and Social Ground Truth in Attappadi, Kerala State, India. Annals of the Association of American Geographers, V. 90(2): 293-321. 
Jackson, Peter 1999. Commodity Cultures: The Traffic in Things. Transactions of the Institute of British Geographers, V. 24(1): 93-108.

Janelle, Donald 2001. Globalization, the Internet Economy, and Canada. The Canadian Geographer, V. 45(1): 48-53.

Jankowski, Piotr and Nyerges, Timothy 2001. GIS-Supported Collaborative Decision Making: Results of an Experiment. Annals of the Association of American Geographers, V. 91(1): 48-70.

Johnston, RJ et al. (eds.) 2000. The Dictionary of Human Geography $4^{\text {th }}$ Edition. Blackwell Publishers Ltd., Oxford.

Johnston, RJ 1997. Geography and Geographers: Anglo-American Human Geography since 1945. Arnold, London.

Kirsch, Scott 1995. The Incredible Shrinking World? Technology and the Production of Space. Environment and Planning D: Society and Space, V. 13: 529-555.

Klein, Juan-Luis et Carrière, Jean 1999. Les Réseaux Territorialisés D’Information Face à la Communication-Monde: Une Expérimentation Québecoise. The Canadian Geographer, V. 43(2): 161-70.

Langton, John 2000. Proletarianization in the Industrial Revolution: Regionalism and Kinship in the Labour Markets of the British Coal Industry from the Seventeenth the Nineteenth Centuries. Transactions of the Institute of British Geographers, V. 25(1): 3149.

Latour, Bruno 1999. Pandora's Hope: Essays on the Reality of Science Studies. Harvard University Press, Cambridge, Mass.

Latour, Bruno 1998. "To Modernise or Ecologise? That is the Question" in Remaking Reality (eds.) B. Braun and N. Castree. Routledge, New York.

Latour, Bruno 1992. "Where are the Missing Masses? The Sociology of a Few Mundane Artifacts" in Shaping Technology/Building Society (eds.) W. Bijker and J. Law. MIT Press, Cambridge, Mass.

Latour, Bruno 1993. We Have Never Been Modern. Harvard University Press, Cambridge, Mass.

Latour, Bruno and Woolgar, Steve 1986. Laboratory Life: The Construction of Scientific Facts. Princeton University Press, Princeton, New Jersey.

Law, John 1994. Organizing Modernity. Blackwell Publishers, Oxford. 
Lefebvre, Alain 1999. Les Autoroutes de l'Information Entre Territoire et Réseaux. The Canadian Geographer, V. 43(2): 118-26.

Leopold, Aldo 1949. "The Land Ethic", in Environmental Philosophy 1998 (ed.) M. Zimmerman, Prentice-Hall Inc, New Jersey.

Leyshon, Andrew and Pollard, Jane 2000. Geographies of Industrial Convergence: The Case of Retail Banking. Transactions of the Institute of British Geographers, V. 25(2): 203-220.

Liverman, Diana 1990. Drought Impacts in Mexico: Climate, Agriculture, Technology, and Land Tenure in Sonora and Puebla. Annals of the Association of American Geographers, V. 80(1): 49-72.

Livingstone, David 1998. Reproduction, Representation and Authenticity: A Rereading. Transactions of the Institute of British Geographers, V. 23(1): 13-19.

Livingstone, David 1990. Geography, Tradition and the Scientific Revolution: An Interpretive Essay. Transactions of the Institute of British Geographers, V. 15(3): 359373.

MacPherson, Alan 1997. The Role of Producer Service Outsourcing in the Innovation Performance of New York State Manufacturing Firms. Annals of the Association of American Geographers, V. 87 No. 1: 52-71.

Manara, Cédric 1999. Réseaux Électroniques et Espaces Juridiques: Expérimentation en Nord-Pas de Calais. The Canadian Geographer, V. 43(2): 170-77.

Massey, Doreen 1999a. Power-Geometries and the Politics of Space-Time. HettnerLecture, Department of Geography, University of Heidelberg.

Massey, Doreen 1999b. Space-Time, 'Science' and the Relationship Between Physical Geography and Human Geography. Transactions of the Institute of British Geographers, V. 24(3): 261-276.

Massey, Doreen 1995a. Spatial Divisions of Labor: Social Structures and the Geography of Production $2^{\text {nd }}$ edition. Routledge, New York.

Massey, Doreen 1995b. Masculinity, Dualisms and High Technology. Transactions of the Institute of British Geographers, V. 20(4): 487-499.

Massey, Doreen 1994. Space, Place, and Gender. University of Minnesota Press, Minneapolis. 
Massey, Doreen et al. 1992. High-Tech Fantasies: Science Parks in Society, Science and Space. Routledge, London.

Mather, Charles 1993. Flexible Technology in the Clothing Industry: Some Evidence from Vancouver. The Canadian Geographer, V. 37(1): 40-47.

McTaggart, Donald 1993. Bioregionalism and Regional Geography: Place, People, and Networks. The Canadian Geographer, V. 37(4): 307-19.

Murdoch, Jonathon 2000. Space against Time: Competing Rationalities in Planning for Housing. Transactions of the Institute of British Geographers, V. 25(4): 503-519.

Murdoch, Jonathon and Marsden, Terry 1995. The Spatialisation of Politics: Local and National Actor-Spaces in Environmental Conflict. Transactions of the Institute of British Geographers, V. 20(3): 368-380.

Ó hUallacháin, Breandán 1997. Restructuring the American Semiconductor Industry: Vertical Integration of Design Houses and Wafer Fabricators. Annals of the Association of American Geographers, V. 87 No. 2: 217-237.

Peet, Richard 1998. Modern Geographical Thought. Blackwell Publishers Inc., Oxford.

Perrault, Ralph 2002. Personal Communications. Carleton University, Ottawa.

Peuquet, Donna 1994. It's About Time: A Conceptual Framework for the Representation of Temporal Dynamics in Geographic Information Systems. Annals of the Association of American Geographers, V. 84(3): 441-461.

Pickles, John 1997. Tool or Science? GIS, Technoscience, and the Theoretical Turn. Annals of the Association of American Geographers, V. 87 No. 2: 363-372.

Relph, E. 1970. An Inquiry into the Relations between Phenomenology and Geography. Canadian Geographer, 14(3): 193-200.

Rigby, David and Haydamack, Brent 1998. Regional Trajectories of Technological Change in Canadian Manufacturing. The Canadian Geographer, V. 42(1): 2-13.

Rigby, David 1991. Technical Change and Profits in Canadian Manufacturing: A Regional Analysis. The Canadian Geographer, V. 35(4): 353-66.

Robbins, Paul 2001. Tracking Invasive Land Covers in India, or Why Our Landscapes Have Never Been Modern. Annals of the Association of American Geographers, V. 91(4): 637-659. 
Rollins, William 1995. Whose Landscape? Technology, Fascism, and Environmentalism on the National Socialist Autobahn. Annals of the Association of American Geographers, V. 85(3): 494-520.

Rose, Damarais and Villemaire, Marc 1997. Reshuffling Paperworkers: Technological Change and Experiences of Reorganization at a Quebec Newsprint Mill. The Canadian Geographer, V. 41(1): 61-87.

Scheibler, Ingrid 1993. "Heidegger and the Rhetoric of Submission: Technology and Passivity" in Rethinking Technologies (ed.) V. Conley. University of Minnesota Press, Minneapolis.

Shapin, Steven 1998. Placing the View from Nowhere: Historical and Sociological Problems in the Location of Science. Transactions of the Institute of British Geographers, V. 23(1): 5-12.

Simpson, Lorenzo 1995. Technology Time and the Conversations of Modernity. Routledge, New York.

Swyngedouw, Erik 1992. Territorial Organization and the Space/Technology Nexus. Transactions of the Institute of British Geographers, V. 17 No. 4: 417-433.

Tehranian, Majid and Ogden, Michael 1998. Uncertain Futures: Changing Paradigms and Global Communications. Futures, V. 30 No. 2/3: 199-210.

Toffler, Alvin 1970. Future Shock. Bantam Books, Toronto.

Unwin, Tim 2000. A Waste of Space? Towards a Critique of the Social Production of Space. Transactions of the Institute of British Geographers, V. 25(1): 11-29.

Vidal, Philippe 1999. Les Sites Web de Quatre Municipalités Françaises au Crible de la Géographie des Représentations. The Canadian Geographer, V. 43(2): 191-97.

Wright, Dwayne, Goodchild, Michael and Proctor, James 1997. GIS: Tool or Science? Demystifying the Persistent Ambiguity of GIS as "Tool" versus "Science". Annals of the Association of American Geographers, V. 87 No. 2: 346-362.

Zimmerman, Michael (ed.) 1998. Environmental Philosophy $2^{\text {nd }}$ Edition. Prentice-Hall Inc., New Jersey.

Zimmerman, Michael 1990. Heidegger's Confrontation with Modernity: Technology, Politics, and Art. Indiana University Press, Indianapolis. 